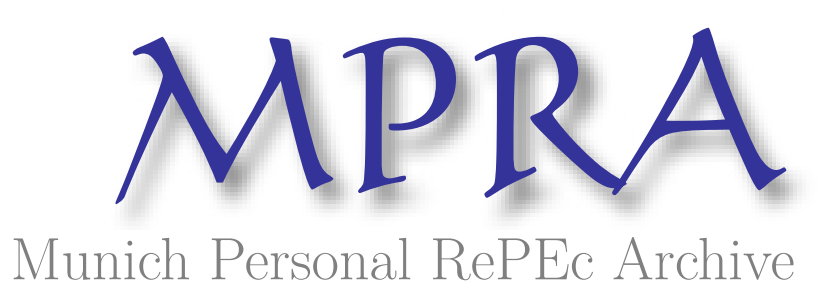

\title{
Resolving the Exposure Puzzle: The Many Facets of Exchange Rate Exposure
}

Bartram, Söhnke M. and Brown, Gregory W. and Minton, Bernadette

1 January 2009

Online at https://mpra.ub.uni-muenchen.de/14041/

MPRA Paper No. 14041, posted 14 Mar 2009 02:10 UTC 


\title{
Resolving the Exposure Puzzle: The Many Facets of Exchange Rate Exposure
}

\author{
Söhnke M. Bartram ${ }^{*}$, Gregory W. Brown ${ }^{+}$, and Bernadette A. Minton ${ }^{\#}$
}

\begin{abstract}
Theory predicts sizeable exchange rate (FX) exposure for many firms. However, empirical research has not documented such exposures. To examine this discrepancy, we extend prior theoretical results to model a global firm's FX exposure and show empirically that firms pass through part of currency changes to customers and utilize both operational and financial hedges. For a typical sample firm, pass-through and operational hedging each reduce exposure by $10 \%$ to $15 \%$. Financial hedging with foreign debt, and to a lesser extent FX derivatives, decreases exposure by about $40 \%$. The combination of these factors reduces FX exposures to observed levels.
\end{abstract}

Keywords: Competition, hedging, FX exposure, derivatives, international finance JEL Classification: G3, F4, F3

January, 2009

\footnotetext{
* Lancaster University, Management School, Department of Accounting and Finance, Lancaster LA1 4YX, United Kingdom, phone: +44 (15 24) 592 083, fax: +1 (425) 95210 70, Email: <s.m.bartram@lancaster.ac.uk>, Internet: $<$ http://www.lancs.ac.uk/staff/bartras1/>.

${ }^{+}$Corresponding Author, Associate Professor of Finance, Kenan-Flagler Business School, The University of North Carolina at Chapel Hill, CB 3490, McColl Building, Chapel Hill, NC 27599-3490 USA, phone: (919) 962-9250, Email: gregwbrown@unc.edu.

\# Associate Professor of Finance, Fisher College of Business, The Ohio State University, 834 Fisher Hall, 2100 Neil Avenue, Columbus, OH 43210-1144 USA, phone: (614)688-3125, Email: minton_15@cob.osu.edu.

The authors wish to thank Eitan Goldman and Merih Sevilir for their assistance with the global version of the BDM model as well as Keith Brown, John Butler, Kalok Chan, Joshua Coval, John Griffin, Neil Kellard, Yrjö Koskinen, Stephen Magee, John Hund, James Ohlson, Mitchell Petersen, DoAnne Sanchez, Matt Spiegel, Roberto Wessels and seminar participants at the 2006 Financial Intermediation Research Society Conference, 2006 FDIC Summer Research Workshop, Bank of Canada, Forum on Corporate Finance, Hong Kong University of Science and Technology, Humboldt University Berlin, London School of Economics, Peking University, State Street Global Advisors, University of North Carolina, University of Texas at Austin, University of Toronto, Warwick Business School, and York University for helpful comments and suggestions. They gratefully acknowledge research funding by the Center for Financial Research of the FDIC and the International Centre for Research in Accounting as well as support by Mike Pacey, Global Reports, and Thomson Financial in establishing the dataset. Florian Bardong provided excellent research assistance.
} 


\title{
Resolving the Exposure Puzzle: The Many Facets of Exchange Rate Exposure
}

\begin{abstract}
Theory predicts sizeable exchange rate (FX) exposure for many firms. However, empirical research has not documented such exposures. To examine this discrepancy, we extend prior theoretical results to model a global firm's FX exposure and show empirically that firms pass through part of currency changes to customers and utilize both operational and financial hedges. For a typical sample firm, pass-through and operational hedging each reduce exposure by $10 \%$ to $15 \%$. Financial hedging with foreign debt, and to a lesser extent FX derivatives, decreases exposure by about $40 \%$. The combination of these factors reduces FX exposures to observed levels.
\end{abstract}




\section{Introduction}

Given the globalization of many industries, foreign exchange rate (FX) fluctuations are a source of uncertainty for many corporations. Empirical studies document significant effects of exchange rate changes on firm cash flows, sales, and competitive positions in product markets (e.g., Hung, 1992; Williamson, 2001). Similarly, theoretical models (such as Bodnar, Dumas, and Marston, 2002) predict that many firms should have significant exchange rate exposures. However, empirical studies have tended to document weak (or non-existent) relations between exchange rate changes and firms' stock prices. ${ }^{1}$

In this paper, we examine the discrepancy between theoretical predictions and observed levels of exchange rate exposure in a broad cross-section of global corporations. Our analysis investigates how firms combine three different mechanisms at their disposal for mitigating exchange rate risk. First, firms can (to varying degrees) pass through to customers the changes in costs due to exchange rate movements. Second, firms can often affect their exchange rate exposure by choosing the location and currency of costs (e.g., where factories are located). Third, firms can utilize an array of financial products, such as foreign currency denominated (FC) debt and FX derivatives, as exchange rate risk management tools. Our results show that each of these factors plays an important role in mitigating observed exchange rate exposure, and together they account for the vast majority of the discrepancy between prior theoretical predictions and observed exposures.

Our analysis has two primary parts. First, we expand the theoretical model of Bodnar, Dumas, and Marston (hereafter BDM, 2002) to examine the exchange rate exposures of a global firm that can compete and produce in both a foreign and local market. In the BDM model, the exporting firm cannot sell in its own market and the local firm cannot produce abroad. By assuming that global foreign exchange rate exposure is a weighted average of a firm's foreign exchange exposure in the foreign market and the domestic market, we can derive optimal passthrough decisions and the resulting foreign exchange exposures of global firms in globally competitive industries. Our model generates exposures as a function of market share, product

1 These studies include, among others, Jorion (1990), Amihud (1993), Bodnar and Gentry (1993), Bartov and Bodnar (1994), Bartov, Bodnar, and Kaul (1996), Choi and Prasad (1995), He and Ng (1998), Chow, Lee and Solt (1997), Griffin and Stulz (2001), and Dominguez and Tesar (2006). 
substitutability, pass-through, sales, and costs in foreign currency which are smaller than the original BDM model under most conditions, and in some cases, the model generates negative foreign exchange rate exposures. Overall, our global competition model allows for a richer, more realistic, set of FX exposures since it allows firms to sell and source both at home and abroad.

Second, we analyze a sample of 1,150 manufacturing firms in 16 countries using our global competition model. We show that pass-through and operational hedging are important for reducing the level of exchange rate exposure. However, after accounting for pass-through and operational hedging, theoretical exposures are still larger than observed exposures on average. ${ }^{2}$ We document that firms with high theoretical exposures are both more likely to have FC debt and more likely to use FX derivatives.

We also conduct an attribution analysis that estimates the magnitude of the reduction in exposure due to each channel for a typical firm. Depending on the level of product substitutability, pass-through reduces exposure by about $10 \%$ to $15 \%$. Operational hedging reduces exposure by similar amounts, while financial risk management (FC debt and FX derivatives) accounts for about a further $40 \%$ reduction in exposure. Altogether, firms reduce their gross exchange rate exposure by about $70 \%$ via the three channels. This reduction results in average exposure values very similar to those estimated from regression models. Consequently, for reasonable parameter values, it is not possible to reject our global competition model after correcting for the estimated effects of financial risk management.

Our analysis augments an empirical literature that examines FX exposure. A number of studies estimate the exchange rate sensitivity of stock prices and typically document small exposures. The results of this paper suggest that these observed estimates are reasonable once the three channels which firms have to mitigate exposure are considered. Other studies report differences in exposures across industry classes and countries (Campa and Goldberg, 1999;

\footnotetext{
${ }^{2}$ In our analysis we consider larger exposures to be simply larger values of calculated exposures, not absolute values. This definition of exposure has little practical effect on our results because the vast majority of the theoretical exposures we calculate are greater than zero.
} 
Bodnar and Gentry, 1993; Marston, 2001; Allayannis and Ihrig, 2001; Williamson 2001). ${ }^{3}$ These findings also are consistent with the range of exposure estimates obtained from our model.

A separate strand of literature examines exchange rate risk premia. Several studies (Dumas and Solnik, 1995; De Santis and Gerard, 1998; and Carrieri, Errunza, and Majerbi, 2006) document significant risk premiums at the aggregate market level, but not the industry level. Francis, Hasan, and Hunter (2008) claim that this is not due to firms hedging currency risk but instead the result of model misspecification which they correct by estimating a conditional pricing model at the industry level. While seemingly contradictory to our results, our model and evidence are actually consistent with both views. For example, we find that on average many firms retain some exchange rate exposure which could carry a risk premium. However, we find significant negative correlations when we compare our measures of hedging with the Francis, Hasan, and Hunter (2008) estimates of the currency risk premium. This is consistent with evidence from our analysis (as well as others) that firms reduce risk with financial hedging.

Recent research also examines the associations between exposure and proxies for operational hedging. For example, Carter, Pantzalis and Simkins (2001) examine the use of derivatives and operational hedges on foreign exchange exposures and document that exposures vary, not only as to whether a firm is a net exporter or net importer, but also across weak and strong dollar states. Allayannis, Ihrig, and Weston (2001) find that operational hedging strategies only benefit shareholders when used in combination with financial hedging strategies. Dewenter, Higgins, and Simin (2005) find evidence that operating hedging may help explain low exchange rate sensitivities of firms during the 1994 peso crisis in Mexico and the 1997 devaluation of the Thai Baht.

Other research has examined the relationship between FX exposure and various types of financial risk management. Allayannis and Ofek (2001), Wong (2000), Simkins and Laux

\footnotetext{
${ }^{3}$ Williamson (2001) shows that auto manufacturers have higher foreign exchange rate exposures if they have high levels of foreign sales and face foreign competition. Consistent with theoretical predictions, changes in exposure are related to changing industry structure (e.g., competition) as well as "large and extended" movements in real exchange rates. Bartram and Karolyi (2006) find that the foreign exchange rate exposure of nonfinancial firms is systematically related to firm characteristics (sales, the percentage of foreign sales in general and in Europe in particular), regional factors (geography, strength of currency) and industry characteristics (competition, traded goods). Other studies examine the association between foreign exchange exposures, macroeconomic conditions, and firm activities. For example, Parsley and Popper (2006) and Dahlquist and Robertson (2001) find significant associations between exchange rate exposures and currency arrangements.
} 
(1996), and Hagelin and Prambourg (2004) document significant negative associations between foreign exchange exposures and the use of financial hedges. Nain (2004) shows that an unhedged firm's foreign exchange exposure increases with the extent of hedging in the industry. This paper adds to these areas of research by quantifying the impact of operational and financial hedging on exposures.

While a large number of studies show that FX derivative use is common among global firms with foreign sales, others question the importance of derivatives for financial risk management. For example, Guay and Kothari (2003) show that the magnitude of derivative use is small compared to firm sales, assets, and income, thus derivatives are a small piece of nonfinancial firms' overall risk profile. Similarly, Brown, Crabb, and Haushalter (2003) show that potential gains from time-series variation in the derivative portfolios of gold mining firms are economically insignificant. The results from our analysis provide a potential resolution of this puzzle as well. Specifically, financial hedging with FC debt appears to have a larger effect on exposure than the use of FX derivatives though the use of both is widespread in our sample.

The paper is organized as follows. Section 2 motivates our analysis with a brief case study of the global automotive industry. Section 3 develops our global competition model for foreign exchange rate exposures and pass-through based on Bodnar, Dumas and Marston (2002). This global competition model is estimated for the sample of manufacturing firms in Section 4. Finally, Section 5 concludes.

\section{Exchange Rate Exposure in the Automotive Industry}

In this section, we present a brief industry case study of global automotive production to motivate our subsequent, broader analysis. We choose the auto industry for several reasons. First, it is a well-known, mature, and competitive industry. In addition, the industry is truly global with major companies headquartered (as well as manufacturing) in Asia, Europe, and North America. The auto industry has a history of being affected by exchange rates and consequently taking exchange rate risk seriously. ${ }^{4}$

\footnotetext{
${ }^{4}$ See, Williamson (2001) as well as anecdotes in "Foreign Exchange Hedging Strategies at General Motors" (2004 Harvard Business School Case) by Mihir Dasai and Mark Veblen.
} 
We collect data from 2003 for a sample of 16 firms from six countries (France, Germany, Italy, Japan, South Korea, and the United States) from WARD'S World Motor Vehicle Data Book. ${ }^{5}$ For most auto manufacturers, the largest fractions of sales occur in their own region. However, firms have geographically diversified production with roughly one third of average output produced outside their home country. In some cases, firms have larger fractions of foreign production than fractions of foreign sales, but most firms produce more than they sell locally (e.g., all Japanese firms). Differences in foreign sales and production are closely related to exchange rate exposures yet firms can operationally hedge with production decisions to manage the exposure. Also of interest is the possible effect of global competition on regional markets. For example, North American firms sell the second largest volume of autos in Europe. ${ }^{6}$ Thus, European firms can have significant foreign exchange exposure from their import competition. However, balanced production and sales for both U.S. and European manufacturers in Europe should tend to limit large competitive exposures. In contrast, some firms choose to have relatively low production relative to sales in certain regions. The most extreme examples are Mazda and Hyundai, which each have sales in North America and Europe greatly exceeding production in those regions.

As noted already, we seek to understand how operating hedges (or lack thereof) combine with competitive forces and financial risk management decisions to determine an overall foreign exchange exposure. Similar to Williamson (2001) and others, we base our analysis on theoretical measures of exposure. For this part of the analysis, we estimate the simple model of exchange rate exposure derived in Bodnar and Marston (2002), which shows that the exchange rate exposure elasticity $(\delta)$ can be expressed as

$$
\delta=h_{1}+\left(h_{1}-h_{2}\right)\left(\frac{1}{r}-1\right)
$$

where $h_{1}$ is the foreign currency denominated revenue as a percent of total revenue, $h_{2}$ is foreign currency denominated costs as a percent of total costs, and $r$ is the firm's profit margin.

\footnotetext{
${ }^{5}$ The detailed data are available on request.

${ }^{6}$ Ford and General Motors both have acquired European automakers. For example, Ford acquired Jaguar in 1989 and Volvo in 1999. General Motors acquired Adam Opel in 1929 and 50\% of SAAB in 1989.
} 
In Table 1, we examine the foreign exchange exposure of global automakers based on this model. The first two columns of Table 1 report the total percentage of foreign sales and the gross profit margin. On average, more than half of automakers' sales are foreign. Gross profit margins are fairly similar across firms with the spread between the lowest (Isuzu) and the highest (Honda) equal to 0.16. The next column reports a value for Gross Exposure, which is an estimate of the FX exposure before accounting for foreign production (i.e., operational hedging) and is obtained by evaluating equation (1) for each firm with $h_{2}$ set equal to zero. These Gross Exposure values tend to be large. The average gross exposure of 2.70 indicates that if automakers produced only in their home country, their stock prices should decline on average $2.7 \%$ in response to $1 \%$ appreciation of the local currency.

The next column of Table 1 labeled Model Exposure reports results obtained from evaluating equation (1) using actual values of foreign production $\left(h_{2}\right)$. The important role of foreign production as an operational hedge is evident from the substantial drop in estimated exposure for each firm. Several companies have estimated exposures close to zero, and the average of all firms drops by more than half to 1.26.

Automakers also use financial tools to manage foreign exchange rate risk. The use of financial risk management tools has grown substantially over the last 30 years to the point where the majority of large corporations with foreign operations use some type of financial instrument that can mitigate FX risk. Two of the most common methods are issuance of FC debt and the use of FX derivatives. ${ }^{7}$ FC debt is widely regarded by financial executives as an effective method for mitigating FX risk. For example, Graham and Harvey (2001) report that $85.8 \%$ of surveyed Chief Financial Officers respond that the ability to provide a 'natural hedge' is important or very important in the decision to use FC debt. Additional evidence that FC debt is used as a financial risk management tool is provided by Allayannis and Ofek (2001).

Financial risk management tools have some distinct advantages over the other types of FX risk mitigations techniques. First, financial decisions are very much under the control of

\footnotetext{
${ }^{7}$ Because local currency debt can be effectively converted to foreign currency debt with FX derivatives, and viceversa, there is not necessarily a clear distinction between these two strategies (see Allayannis, Brown, and Klapper, 2003). For example, synthetic FC debt can be created using a currency swap. Synthetic FC debt might be preferable to natural FC debt for tax, accounting, and regulatory reasons.
} 
financial managers and less subject to constraints in the product market (e.g., geographic availability of skilled labor and raw materials or the competitive landscape of the local market). Second, financial hedges are likely to have low implementation costs, and positions are usually reversible or easily adjusted. Third, while financial hedges introduce some new risk such as counterparty risk, they are unlikely to introduce risks that might be associated with some operational hedges (e.g., the risk of foreign assets being expropriated or nationalized). On the other hand, financial risk management tools, especially FX derivatives, can have relatively short horizons.

The next columns report the outstanding value of FC debt and FX derivatives as a percent of firm value. All of the automakers use FX derivatives to some extent, though some (like Mitsubishi and Renault) are clearly much larger users than others (like Ford and Toyota). On average, automakers hold FX derivatives with notional values equal to $0.41 \%$ of firm value. ${ }^{8}$ Automakers' use of FC debt, while relatively low, also reduces their exchange rate exposure. ${ }^{9}$

The next column of Table 1 adjusts the Model Exposure numbers by subtracting the level of foreign exchange rate derivatives and foreign currency debt to obtain an estimate of Residual Exposure. These values for Residual Exposure are our estimates of theoretical foreign exchange rate exposure taking into account the level of foreign sales, industry competition (via gross profit margin), operational hedging (via foreign costs), and financial hedging (via FX derivatives and FC debt). On average, these values are considerably lower than the estimates for the Model Exposure. The Residual Exposures range from negative values to positive values, much like the values for Regression Exposure derived from a regression model (and tabled in the following column). ${ }^{10}$

\footnotetext{
${ }^{8}$ The notional amount of derivatives contracts is most likely a noisy signal of the amount of hedging (or speculation) undertaken by a firm and is not available for all of our sample firms. In later empirical results, we use an indicator variable equal to one if a firm utilizes FX derivatives (and zero otherwise) as a proxy for FX derivatives use.

${ }^{9}$ The use of FC debt is sometimes difficult to determine for automakers because of poor disclosure by some firms, so we make conservative assessments in obtaining these values.

${ }^{10}$ Following the existing literature on exchange rate exposure, we regress separately for each firm its excess stock return on the excess return of the local market index (Market) and the percentage change in a trade-weighted exchange-rate index (FX). The regressions are estimated using weekly data for the period from 2000 to 2004. Overall, the results in Table 1 show that firms have either no statistically significant foreign exchange exposure or positive exchange rate exposure. The exchange rates are defined in terms of local currency per unit of the foreign currency. Thus, a positive coefficient estimate is consistent with extant research results on the exposure of exporting
} 
In summary, this section has used global automakers, and a simplified, stylized model, to illustrate how various factors such as the competitiveness of a firm, operational hedging, and financial hedging can have dramatic effects on foreign exchange rate exposure.

\section{An Expanded Empirical Framework}

The primary goal of our analysis is to better understand empirical facts, but to properly account for all relevant factors it is necessary to have a specific model of exposure. Despite the encouraging results presented in the previous section, the calculated Residual Exposure still (i) overestimates exposures on average and (ii) predicts a wider range of exposures than actually observed among automakers. One potential explanation for these results is our use of a relatively simple model as an illustrative example. Specifically, the model is for a monopolist with exogenously specified cash flows. In the preceding analysis, we analyze the effect of product market competition on foreign exchange rate exposure with the naive assumption that the gross profit margin is a sufficient statistic for describing a firm's level of overall competitiveness. In this section, we present a more realistic model of the foreign exchange rate exposure of a global firm in a globally competitive market based on the results of Bodnar, Dumas, and Marston (2002).

A variety of theoretical studies (such as Adler and Dumas, 1984; Hekman, 1985; Shapiro, 1975; Flood and Lessard, 1986; von Ungern-Sternberg and von Weizsäcker, 1990; and Marston, 2001) develop models of FX exposure. In a recent paper, Bodnar, Dumas, and Marston (2002) derive a model of FX exposure that explicitly incorporates industry competition and optimal export pricing behavior. Specially, BDM develop a model of exporting firms under duopoly to study exchange rate exposure and pass-through behavior of firms. BDM examine a firm selling in a foreign market. The firm in their model can produce (i.e., have costs) in both the local and the foreign country, and it competes with another firm that produces (i.e., has costs) only in the foreign market. BDM are able to derive optimal pass-through decisions and the resulting exchange rate exposure. They show that as substitutability between home-produced and foreignproduced goods increases, exposure increases and pass-through declines (holding market shares

or import-competing firms (e.g., Bartram, 2004). The coefficient on the trade-weighted exchange-rate index is positive and significant at the $5 \%$ confidence level for only five of the 16 firms. 
constant). Holding product substitutability fixed, increases in market share reduce both exposure and pass-through elasticities. BDM also provide an empirical analysis using Japanese exporting industries, however the empirical results are mixed. ${ }^{11,12}$

In some ways, the analysis of the location of costs and the effects of market competition on pricing policy examined by BDM are related to mechanisms characterized in the literature as 'operational hedges.' For instance, several theoretical models explicitly model how firms should choose the location of production facilities (i.e., the currency of costs) in the presence of FX risk (Mello, Parsons, and Triantis, 1995, and Chowdhry and Howe, 1999). ${ }^{13}$ While locating a production facility in a foreign country reduces exposure by aligning costs with revenues, and passing-through exchange rate changes to output prices reduces exposure by aligning revenues with costs, the two methods differ in some respects. For example, the location of production is largely under the control of management (though it may be costly to change) and is a real investment decision for the firm. To the contrary, the ability to pass-through price changes depends on the nature of competition in the product market and is presumably not under the immediate control of management if managers choose a value-maximizing strategy. Consequently, each mechanism is likely to be important when determining overall FX exposure.

Here we present a more realistic model of the foreign exchange rate exposure of a global firm in a globally competitive market based on the results of Bodnar, Dumas, and Marston (2002). While the BDM model very precisely examines the effect of competition and the currency denomination of costs on exchange rate exposure, its empirical relevance is limited by simplifying assumptions. To facilitate our empirical analysis, we extend the BDM model in two straightforward ways. First, we consider a market where both firms have costs in local and

\footnotetext{
${ }^{11}$ In three of the eight industries studied, the parameter estimates of exposures are too small to be consistent with either the quantity or price model. For the quantity competition model, three of the remaining five industries have estimates within the theoretical limits of the model. Estimates for five of the industries under the price competition model are within the theoretical limits of the model.

${ }^{12}$ In related work, Dekle (2005) studies the impact of substitutability between foreign and export products and the type of competition on exchange rate exposure. For 15 Japanese export industries, product substitutability is found to be high, and ten of these 15 industries are better characterized as Cournot competitors in foreign markets than as colluders. Consistent with the theoretical predictions of the paper, collusive exporters tend to have higher elasticities than competitive exporters.

${ }^{13}$ The general method in the theoretical literature has been to focus on deriving either optimal pricing policies (i.e., considering production locations and costs fixed) or optimal location of production (e.g., considering unit prices fixed).
} 
foreign currency. Second, we consider firms that sell both locally and in foreign markets. These extensions of the BDM model make it applicable to a much broader sample of global firms and produce an expanded set of predicted exchange rate exposures. ${ }^{14}$ For example, our model considers the case of a firm that produces in a foreign market, sells in the local market, and faces import competition. This firm can have a negative exposure to exchange rate changes something not allowed for in the original BDM model. We refer the reader to BDM for a full discussion of the base model and begin our analysis with the derivation of a global firm's exchange rate exposure.

\subsection{Exchange Rate Exposure of a Global Firm that Competes Globally}

Total exchange rate exposure for a global firm $(\delta)$ is defined as the sales-weighted average of exchange rate exposures from foreign operations $\left(\delta_{f}\right)$ and domestic operations $\left(\delta_{d}\right)$ so that

$$
\delta=\phi \delta_{f}+(1-\phi) \delta_{d}
$$

where $\phi$ is the percentage of foreign sales. ${ }^{15}$ To keep the analysis tractable, we proceed by assuming that two symmetric firms compete in a single foreign market and derive the exposure of each firm. In particular, we interpret the exposure from foreign operations $\left(\delta_{f}\right)$ as the exposure of a firm that produces domestically and abroad, but sells all of its output abroad (exporter). Similarly, we interpret the exposure from domestic operations $\left(\delta_{d}\right)$ as the exposure of a firm that produces domestically and abroad, but sells all of its output at home (import-competing firm). Of course, the essential difference in exposure between the local firm and the foreign firm is the reported currency denomination of profits, since each is potentially "global" with regards to its production and sales.

For the derivation of the exposure of the exporter, "foreign" always refers to the country of firm 2 (the foreign, import-competing firm) and "domestic" always refers to the country of

\footnotetext{
${ }^{14}$ Because our goals are ultimately empirical (and to keep the exposition parsimonious), we examine only quantity competition. However, expanding the analysis so as to also examine price competition would be straightforward.

${ }^{15}$ This is equivalent to assuming that a global firm is made up of completely separate domestic and foreign divisions that can be examined independently.
} 
firm 1 (the exporter). To facilitate the exposition, we conform to the notation of BDM and define the profits of the exporter in its domestic currency $\left(\pi_{1}^{*}\right)$ in local currency as

$$
\pi_{1}^{*}=S P_{1} X_{1}-\left(C_{1}^{*}+S C_{1}\right) X_{1}
$$

And the profits of the import-competing firm in its domestic currency as

$$
\pi_{2}=P_{2} X_{2}-\left(\frac{C_{2}^{*}}{S}+C_{2}\right) X_{2}
$$

where $S$ is the exchange rate (in domestic currency relative to foreign currency), $P_{i}$ is the equilibrium price of firm $i$ 's product, $X_{i}$ is the equilibrium quantity of product sold by firm $i$, and $C_{i}^{*}\left(C_{i}\right)$ are the marginal costs in local (foreign) currency $(i=1,2)$. However, we note that unlike BDM, we allow both firms to have costs in foreign currency so that the relative cost ratio in local currency is

$$
R=\frac{C_{2}^{*}+S C_{2}}{C_{1}^{*}+S C_{1}} .
$$

In Appendix A, we show that the equilibrium exposure measures $\delta_{f}$ and $\delta_{d}$ are equivalent to

$$
\begin{gathered}
\delta_{f}=\frac{d \ln \pi_{1}^{*}}{d \ln S}=1+\left(1-\lambda_{f}\right) \rho_{f} \mu_{f}+\frac{\left(1-\lambda_{f}\right) \lambda_{f} \rho_{f}^{2} \mu_{f}}{1-\rho_{f}\left(1-\lambda_{f}\right)} \\
\delta_{d}=\frac{d \ln \pi_{2}}{d \ln S}=\left(1-\lambda_{d}\right) \rho_{d} \mu_{d}+\frac{\left(1-\lambda_{d}\right) \lambda_{d} \rho_{d}^{2} \mu_{d}}{1-\rho_{d}\left(1-\lambda_{d}\right)}
\end{gathered}
$$

where for $j \in(d, f)$,

$$
\mu_{j}=\left(1-\gamma_{j 1}\right) \gamma_{j 2}-\gamma_{j 1}\left(1-\gamma_{j 2}\right),
$$

$\lambda_{j}$ is the equilibrium market share in market $j$,

$\gamma_{j i}$ is the fraction of marginal costs in foreign currency in market $j$ for firm $i$, and

$\rho_{j} \in(0,1)$ measures substitutability between the firms' products in market $j$.

Thus, the overall exchange rate exposure for a global firm can be expressed as 


$$
\delta=\phi\left[1+\left(1-\lambda_{f}\right) \rho_{f} \mu_{f}+\frac{\left(1-\lambda_{f}\right) \lambda_{f} \rho_{f}^{2} \mu_{f}}{1-\rho_{f}\left(1-\lambda_{f}\right)}\right]+(1-\phi)\left[\left(1-\lambda_{d}\right) \rho_{d} \mu_{d}+\frac{\left(1-\lambda_{d}\right) \lambda_{d} \rho_{d}^{2} \mu_{d}}{1-\rho_{d}\left(1-\lambda_{d}\right)}\right]
$$

While our exposure expression is significantly more complicated than the original BDM model, the underlying factors determining exposure are the same. In fact, the exposure equation from BDM is a special case of the above equation where $\phi=1$ and $\gamma_{f 2}=1$. The terms $\mu_{f}$ and $\mu_{d}$ capture the combined relative effects of marginal costs in foreign currency for firm $1\left(\gamma_{f l}\right)$ and firm $2\left(1-\gamma_{f 2}\right)$.

Since $0 \leq \gamma_{j 1}$ and $\gamma_{j 2} \leq 1$, it follows that $-1 \leq \mu_{j} \leq 1$. Therefore, in our model the lowest obtainable exposure is -2.0 as opposed to +1.0 in the BDM model. A highly negative exposure would be predicted for a firm that produces abroad, sells locally, has competitors that produce locally, has a high degree of product substitutability, and has low market share. The negative exposure in this case is intuitive because this type of firm would benefit from an appreciating local currency. Overall, our global competition model allows for a wide range of negative exposures and positive exposures (up to +3.0). These positive exposures are expected for most firms that have exporting activities or face import competition.

\subsection{Exchange Rate Pass-Through of a Global Firm that Competes Globally}

In a similar way, we derive the pass-through of exchange rate risk for a global firm as the foreign sales-weighted average of pass-through from foreign operations $\left(\eta_{f}\right)$ and domestic operations $\left(\eta_{d}\right)$

$$
\eta=\phi \eta_{f}+(1-\phi) \eta_{d}
$$

Pass-through is defined as the partial derivative of the equilibrium price of firm $i$ 's product, $P_{i}$, to the exchange rate. Appendix B shows that the equilibrium pass-through measures $\eta_{f}$ and $\eta_{d}$ are obtained as

$$
\begin{aligned}
& \eta_{f}=\frac{d \ln P_{1}}{d \ln S}=\left(\gamma_{f 1}-1\right)+\lambda_{f} \rho_{f}\left[\left(1-\gamma_{f 1}\right) \gamma_{f 2}-\gamma_{f 1}\left(1-\gamma_{f 2}\right)\right] \\
& \eta_{d}=\frac{d \ln P_{2}}{d \ln S}=\left(1-\gamma_{d 2}\right)+\lambda_{d} \rho_{d}\left[\left(1-\gamma_{d 1}\right) \gamma_{d 2}-\gamma_{d 1}\left(1-\gamma_{d 2}\right)\right] .
\end{aligned}
$$

Thus, the overall pass-through of exchange rate risk by the global firm can be expressed as 


$$
\eta=\phi\left[\left(\gamma_{f 1}-1\right)+\lambda_{f} \rho_{f} \mu_{f}\right]+(1-\phi)\left[\left(1-\gamma_{d 2}\right)+\lambda_{d} \rho_{d} \mu_{d}\right],
$$

where all parameters are defined as above for the foreign exchange rate exposure of the firm $(\delta)$. This pass-through expression also is more involved compared to the BDM model, but again the

original model is subsumed as a special case for parameter values $\phi=1$ and $\gamma_{f 2}=1$. (BDM multiply their pass-through estimates by minus one so that the elasticity is positive.) In the BDM model, pass-through is between zero and one. In contrast, pass-through, $\eta$, ranges from negative one to positive one $(-1<\eta<+1)$ in our model.

\subsection{Global Competition Model Analysis and Comparative Statics}

Figure 1 plots the feasible space of exchange rate exposures as a function of product substitutability $(\rho)$. The shaded area above $\delta=+1.0$ represents the exchange rate exposures allowed by the BDM model for various values of $\rho$. The shaded area below +1.0 represents the additional range of exchange rate exposures for global firms that compete with other global firms in our model. Given that prior empirical work documents that most firms have low exchange rate exposures, this additional range has substantial empirical relevance. The fact that the range of theoretical exposures expands as product substitutability increases reinforces the notion that product market competition can have a significant effect on firms' exchange rate exposures.

A key aspect of the global competition model is the ability to consider the exposure of firms with both foreign and domestic sales. This aspect of the model is reflected in $\mu_{f}$. More specifically, the second term of $\delta_{f}$ captures the impact of the exchange rate on the share of total foreign expenditures accruing to the exporting firm. Unlike BDM, this term can be zero and in some cases negative. The sign of this second term will depend on the magnitude of $\mu_{f}$. Recall that

$$
\mu_{f}=\left(1-\gamma_{f 1}\right) \gamma_{f 2}-\gamma_{f 1}\left(1-\gamma_{f 2}\right)
$$

where $\gamma_{f 1}$ and $\left(1-\gamma_{f 2}\right)$ represent the fraction of marginal costs due to foreign currency based inputs for firm 1 and firm 2, respectively. The smaller the fraction of foreign cost of firm 1 and the larger the fraction of foreign cost for firm 2 , the larger is the value of $\mu_{f}$. For example, if $\gamma_{f 1}=(1$ $\left.\gamma_{f 2}\right)=0.1$, then $\mu_{f}$ equals 0.8 . In contrast, if $\gamma_{f 1}=\left(1-\gamma_{f 2}\right)=0.7$, then $\mu_{f}$ equals -0.4 . Finally, $\mu_{f}$ equals zero when $\gamma_{f 1}=\gamma_{f 2}$. 
The third term of $\delta_{f}$ captures the impact of the foreign exchange rate on the domestic currency profit margin of the exporter. Like the second term, the sign and magnitude of the third term will depend on $\mu_{f}$. If $\mu_{f}$ is negative (positive), then the third term is negative (positive). As noted already, $\mu_{f}$ can be zero, and thus, the third term will also be zero if $\gamma_{f 1}=\gamma_{f 2}$. Since the model is symmetric, similar arguments apply to $\mu_{d}$, the relative costs in foreign currency for firm 1's domestic market. Altogether, these results show that for a global firm both the sign and the magnitude of the exchange rate elasticity depends on the sign and magnitude of the relative costs in foreign currency, $\mu_{j}$. The wider range of allowed exposures in our global competition model are important because most of the regression exposures estimated in prior empirical work are below the minimum values allowed for by the BDM model (even after making an adjustment for the fact that the BDM model assumes that all sales are in the foreign country).

To obtain an intuitive feel for the relative importance of the various model inputs, we examine exposures for a range of parameter values. Figure 2 shows plots of exposure (on the vertical axis) as a function of the model input parameters where we hold all parameters, besides the one of interest, fixed at values close to the averages of sample firms we subsequently examine. ${ }^{16}$ Panel A shows exposure for values of the percentage of foreign sales $\left(\phi_{f}\right)$ ranging from $0 \%$ to $100 \%$. As expected, exposure values increase rapidly with the level of foreign sales. The exposure for a firm with no foreign sales is close to zero (0.03) whereas a pure exporter will have an exposure of around 1.2.

Panel B shows the sizeable effect of foreign costs $\left(\gamma_{f 1}\right)$ on exposure. As foreign costs increase, the natural hedge from foreign operations reduces exposure significantly from about 0.8 for a firm with no foreign costs to about 0.3 for a firm with only foreign costs. One explanation for this reduction is given by Pringle and Connolly (1993). They note that economic exposure exists when real exchange rates move (i.e. changes in the nominal exchange rate are not offset by changes in the inflation rates). Unlike FX derivatives which fix the nominal FX rate but leave the inflation differential unaffected, operational hedges allow both the nominal exchange rate and inflation differential to move and offset each other, and therefore are effective hedges.

\footnotetext{
${ }^{16}$ Specifically, for the base case we set $\phi_{f}=0.5, \gamma_{f 1}=0.3, \gamma_{d l}=0.6, \gamma_{f 2}=0.6, \rho_{f}=\rho_{d}=0.7, \lambda_{f}=0.3$, and $\lambda_{d}=0.7$.
} 
Panels $\mathrm{C}$ and $\mathrm{D}$ show the effects on exposure of competitors cost structures in both the domestic and foreign markets. Panel $\mathrm{C}$ reveals that as competitors' costs in the domestic market $\left(\gamma_{d l}\right)$ are denominated more in local currency, exposure declines though the effect is relatively small (since for the base case most exposure comes from foreign operations). Panel D reveals the greater sensitivity to the currency of competitors' costs in the foreign market $\left(\gamma_{f 2}\right)$. Specifically, as competitors' costs switch from all domestic to all foreign currency, the firm's exposure increases from 0.41 to 0.76 .

Panel E of Figure 2 shows that as product substitutability increases so does exposure. The non-linear relationship highlights the importance of product market competition in determining overall exposure, and in particular, that firms in very competitive industries face disproportionately high relative exposures.

Finally, Panel F plots the relationship between exposure and the degree of import competition. The graph reveals the relatively low sensitivity to the percentage of competition that comes from imports in the foreign market $\left(\lambda_{f}\right)$. For the full range of possible values, exposure only varies by about 0.1 . A similar, but even weaker, relationship holds for the percentage of competition that comes from imports in the domestic market $\left(\lambda_{d}\right)$ so we do not plot it here.

An important part of overall exchange rate exposure for global firms is determined by how much of exchange rate exposure can be passed through to customers via price changes. In the global competition model, the relationship between product market characteristics and passthrough can be quite complex. For example, pass-through can decrease or increase with increases in product substitutability. To see this, recall that the impact of product substitutability depends on the values of $\mu_{f}$ and of $\mu_{d}$. Consider

$$
\mu_{f}=\left(1-\gamma_{f 1}\right) \gamma_{f 2}-\gamma_{f 1}\left(1-\gamma_{f 2}\right),
$$

where $\gamma_{f 1}$ and $\left(1-\gamma_{f 2}\right)$ represent the fraction of marginal costs due to foreign currency based inputs for firm 1 and firm 2, respectively. The smaller the fraction of foreign cost of firm 1 and the larger the fraction of foreign cost for firm 2 , the larger is the value of $\mu_{f}$. Since the model is symmetric, similar arguments apply to $\mu_{d}$, the relative costs in foreign currency for firm 1's 
domestic market. Thus, for a global firm, both the sign and the magnitude of pass-through depend on the sign and magnitude of the relative costs in foreign currency.

Market share also impacts the size of pass-through. Considering $\eta_{f}$, the sign and magnitude of $d \eta_{f} / d \lambda_{f}$ depends on the sign and magnitude of the relative costs in foreign currency, $\mu_{f}$, and the magnitude of product substitutability such that

$$
\frac{d \eta_{f}}{d \lambda_{f}}=\rho_{f} \mu_{f}
$$

Thus, higher market share increases pass-through when $\mu_{f}$ is negative (i.e., pass-through is more negative and larger). In this case, the fraction of foreign cost of firm 1 is larger and the fraction of foreign cost for firm 2 is smaller. If, on the other hand, $\mu_{f}$ is positive, higher market share decreases pass-through.

Altogether, the results in this section show that for a global firm both the sign and the magnitude of the exchange rate elasticity (exposure) and pass-through depend on the sign and magnitude of the relative costs in foreign currency, $\mu_{j}$. With the model in hand, we now turn to an analysis of exchange rate exposure using a large sample of global corporations.

\section{Estimation of the Global Competition Model}

\subsection{Data}

The initial sample includes all publicly traded manufacturing firms with sufficient accounting data for either the year 2000 or 2001 on the Thomson Analytics database and that have at least 25 non-missing monthly stock returns on Datastream during the 1998-2002 period. We also require firms to have an annual report in English for the same year on the Global Reports database, and the required trade data at the industry and country level (described below). ${ }^{17}$ Our final sample is comprised of 1,150 firms from 16 countries. Table 2 reports how the sample size is reduced by successive data requirements. The requirement of trade data is the most limiting in terms of number of countries and the English language annual report requirement (necessary for financial hedging data) is the most restrictive for individual firms. We also lose a significant

\footnotetext{
${ }^{17}$ Global reports (www.global-reports.com) is an online information provider of public company documents in portable document format (PDF).
} 
number of firms because they do not report foreign sales and assets or there are no other firms in their industry reporting foreign sales or assets. Panel B of Table 2 shows the industry and country composition of our sample. Sample firms come from a wide variety of manufacturing sub-industries with the largest industry (electronic equipment) representing $13.0 \%$ of the sample. Because of our reliance on English language annual reports, the country composition is biased toward the U.S., U.K., and Canada with firms from these four countries making up about threequarters of the sample. Japan, because of its large economy and manufacturing industry, contributes about $12 \%$ of sample firms.

Accounting data including information on foreign sales and foreign assets originate from the Thomson Analytics database. ${ }^{18}$ To reduce the effect of data errors, we exclude observations that fall in the top and bottom one percentile or whose value exceeds five standard deviations from the median. ${ }^{19}$ We collect data on FC debt and FX derivatives use via an automated search of each firm's fiscal year 2000 or 2001 annual report. We create dichotomous variables for the use of foreign currency debt and foreign exchange rate derivatives usage.

Firms are classified into industries on the basis of four-digit SIC codes. For the years 1999, 2000 and 2001, data on industry competitiveness, production, exports and imports are collected from various sources as follows: We generate measures of import competition using the United Nations Industrial Development Organization (UNIDO) Industrial Statistics Database and the Structural Statistics for Industry and Services (SSIS) database of the OECD. Trade data are used to calculate an import penetration ratio by taking imports as a percent of imports plus domestic production. ${ }^{20}$ We also obtain GDP data and calculate for each country and industry a measure of foreign import penetration as weighted averages of the import penetration variables of all foreign countries. Because the UNIDO data are only available by International Standard

\footnotetext{
${ }^{18}$ These data are generated from geographical segment data. In most cases, foreign sales data include both sales by international business units (IBUs) as well as direct exports. In the cases where IBUs exist the company will also have foreign assets. In some cases where sales are made to local branches of foreign affiliates the reported foreign sales data might under-estimate the effective level of foreign sales.

${ }^{19}$ In order to minimize the potential influence of the economic cycle, we use three-year averages of variables where this impact seems most relevant (e.g., gross profit margin).

${ }^{20}$ Similar results are obtained by using a permutation of imports as a percent of production plus imports minus exports. However, this measure can have extreme values in countries with large exports in certain industries, so we do not use it in the primary analysis.
} 
Industry Classification (ISIC, Rev. 3), we calculate for each four-digit SIC code the mean of the statistics for the corresponding ISIC. In addition, we calculate Herfindahl indices using all WorldScope firms with sales data to measure competition at the industry and country level. For all of these measures, we use the value in the year prior to the firm observation. ${ }^{21}$

All capital market data (i.e., the firms' stock returns, stock index returns, interest rates, and exchange rates) are from Datastream for the period 1998 to 2002 . $^{22}$ We use monthly return series for up to five years to reduce microstructure effects such as bid-ask bounce and because prior research suggests longer time frames provide more accurate exposure estimates (e.g., Chow, Lee, and Solt, 1997). For each firm, we calculate stock returns in local currency, local currency returns of the corresponding Datastream national stock market index, and the percentage change in a trade-weighted foreign exchange rate index (in local currency relative to the basket of foreign currencies). We exclude the return observations in the top and bottom $0.1 \%$ to mitigate some obvious data errors. Consistent with prior research, we use these data to estimate augmented market model (time series) regressions that include returns on exchange rate indices. Specifically, we estimate for each firm

$$
R_{j t}=\alpha_{j}+\beta_{j M} R_{M t}+\beta_{j F X} R_{F X t}+\varepsilon_{j t},
$$

where $R_{j t}$ is the local currency stock return in excess of the risk-free rate, $R_{M t}$ is the local currency return of the market index in excess of the risk-free rate, and $R_{F X t}$ is the percentage change of the exchange rate index. The resulting coefficients on the exchange rate variable $\left(\beta_{F X}\right)$ represent our estimates for regression (firm-specific) exchange rate exposure. In the subsequent analysis we call these estimates regression exposures. While studies have shown that exposure estimates depend on the precise specification (i.e., choice of exchange rate and market index as in Bodnar and Wong, 2003), our specification is consistent with much of the current literature.

\footnotetext{
${ }^{21}$ In a few cases, industry data are not available for the prior year, in which case we use the value from 2 years prior.

22 These dates are chosen because they surround our FX derivatives and FC debt observations. While several unusual events happened during this period (e.g., Russian default, introduction of the Euro, technology stock market bubble, market closures after terrorist attacks of September 11, 2001), equity volatilities, exchange rate volatilities, and the correlations between equity returns and exchange rates appear unremarkable. To determine this we examine each of these variables for the eight preceding years (1990-1997) and the following six years (2003-2008) for Canada, Japan, the United Kingdom, and the United States and find that values for the 1998-2002 period are not consistently higher or lower than in the contiguous periods.
} 
Better measures of exposure could be estimated by creating a firm-specific exchange rate index, but the necessary geographic segment data necessary for this calculation are unavailable for many of our firms. Still, we examine exposure estimates from alternative versions of the model in equation (12). ${ }^{23}$ The conclusions of our analysis are largely unaffected because alternative methods tend to yield higher values of $\beta_{F X}$ which tends to reduce the gap between theoretical measures of exposure and measures obtained from stock prices.

Table 3 reports summary statistics for the full sample. The first row reports regression foreign exchange rate exposures obtained from equation (12). Exposures average 0.160 with a standard deviation of 1.972. The inner quartile runs from -0.701 to 1.260 . Because the model we examine does not account for financial leverage, we multiply the estimated exposure by the market value of equity divided by firm value to obtain estimates of unlevered foreign exchange rate exposure. These values, which are reported in the second row of Table 3, are very similar to the unadjusted exposure values though, obviously, somewhat smaller in magnitude.

Table 3 also reports that foreign sales average $34.6 \%$ of total sales, and foreign assets average $19.2 \%$ of total assets. Overall, $87.1 \%$ of the firms in our sample have FC debt, and $65.8 \%$ use FX derivatives. Import penetration averages $24.1 \%$ for the country-industry combinations in which our sample of firms operate.

\subsection{Model Parameters and Estimated Exposures}

In order to make the global competition model operational, it is necessary to find acceptable proxies for each of the input parameters. Table 4 lists the required parameter inputs for the model, their description, and the empirical proxy that we utilize. As our proxy for $\phi$, we use foreign sales as a percent of total sales. Measures of $\gamma$ (fractions of marginal costs in foreign currency) are not as straightforward. Intuitively, the various $\gamma$ parameters describe the currency of costs for a firm and its competitors in both domestic and foreign markets. As a proxy for foreign productive capacity, we use the ratio of foreign assets to total assets. Thus, our proxy for $\gamma_{f l}$, the firm's fraction of marginal costs in the foreign market due to foreign currency inputs, is

\footnotetext{
${ }^{23}$ For example, we utilize market returns that are orthogonal to changes in the exchange rate index and exposure estimates from a model with only changes in the exchange rate index (i.e., no excess market returns). We also examine shorter estimation periods and higher frequency (daily and weekly) returns.
} 
the ratio of foreign assets to total assets. Likewise, our proxy for $\gamma_{d 2}$, the firm's fraction of marginal costs in the domestic market, is one minus the ratio of foreign assets to total assets.

We calculate the competitors' costs by market and currency by taking a weighted average of $\gamma_{f 1}$ and $\gamma_{d 2}$ for all other firms in the same industry. Specifically, we calculate $\gamma_{f 2}$, the competitors' fraction of marginal costs in the foreign market due to foreign currency inputs, as the weighted average of percentage of foreign assets of domestic firms $\left(\gamma_{f 1}\right)$ and percentage of domestic assets of all foreign firms in the same industry $\left(\gamma_{d 2}\right)$. Specifically, to construct the proxy for $\gamma_{f l}$, we calculate the foreign sales-weighted average of $\gamma_{f 1}$ for all domestic firms in the same industry and country. The proxy for $\gamma_{d 2}$, is calculated as the domestic sales-weighted average of $\gamma_{d 2}$ for all firms in the same industry in all other countries. These measures are averaged using our measure of foreign import penetration (the GDP-weighted average of the import penetration ratio of all other countries) and one minus this measure as weights, respectively. In the same vein, the competitors' fraction of marginal costs in the domestic currency is calculated as the weighted average of $\gamma_{d 2}$ for local firms in the same industry and $\gamma_{f 1}$ for foreign firms. Here, we use the import penetration ratio and one minus the import penetration ratio as weights.

The parameters $\lambda_{f}$ and $\lambda_{d}$, respectively, represent the market shares of the firm in the foreign and domestic market. Intuitively, these parameters measure the level of competition from foreign firms in the domestic and foreign markets. Consequently, we utilize import penetration ratios for the firm's industry to calculate our proxies for these values. Specifically, we set $\lambda_{f}$ equal to the rest-of-world GDP-weighted average of import penetration ratios, and $\lambda_{d}$ equal to one minus the domestic market import penetration ratio. The final parameters necessary for estimating the model are $\rho_{f}$ and $\rho_{d}$, the degrees of product substitutability in the foreign and domestic markets. These parameters are specified exogenously. In our empirical tests, we set $\rho_{f}$ $=\rho_{d}=0.7$. However, we also frequently report results for values of $\rho$ that are appreciably lower $\left(\rho_{f}=\rho_{d}=0.5\right)$ and higher $\left(\rho_{f}=\rho_{d}=0.9\right)$ so we can examine the effects of product substitutability as well as discuss the robustness of our findings. ${ }^{24}$

\footnotetext{
${ }^{24}$ These values of $\rho$ seem reasonable given the results of BDM who calculate product substitutabilites in the range of 0.7 to 1.0 though in several of the industries studied the (implied) parameter cannot be solved for. We also
} 
Table 5 reports selected descriptive statistics on the model parameters for our sample of firms. Average production cost parameters vary substantially for firms and their competitors in both the domestic and foreign markets. The firm's percentage of foreign currency costs in the foreign market, $\gamma_{f 1}$, averages $19.1 \%$, but the inner quartile ranges from $2.2 \%$ to $27.7 \%$. The low average value is intuitive, since most markets are dominated by domestic firms. Similarly, the average firm's fraction of marginal cost in domestic currency, $\gamma_{d 2}$, is quite high with an average of $80.9 \%$. The competitors' costs in the foreign market, $\gamma_{d 1}$, average $63.1 \%$, which reflects that this is a combination of the fraction of foreign costs for exporters and the fraction of domestic cost for other import-competing firms. Similar values are obtained for the percentage of domestic costs of competitors, $\gamma_{f 2}$, since this is also a weighted average of the fraction of domestic costs of other exporters and the fraction of foreign costs of import-competing firms. Overall, the values for currency denomination of production costs seem very plausible.

Table 5 also reports the values for the relative costs by currency for the foreign and domestic markets, $\mu_{f}$ and $\mu_{d}$, respectively. Recall, that the parameter equivalent to $\mu_{f}$ for the original BDM model is restricted to positive values because the competing firm's costs were only allowed to be in foreign currency. In contrast, in the global competition model, we find that our proxy for $\mu_{f}$ is positive on average $(0.470)$, but it is negative in some cases. This suggests that the second and third terms of the $\delta_{f}$ will sometimes reduce exposure rather than always increase exposure (as is suggested by the original BDM model). As expected, our proxy for $\mu_{d}$ is positive and fairly small in magnitude (0.177) which indicates that, on average, domestic operations also generate some exchange rate exposure. Estimated values for $\lambda_{f}$ and $\lambda_{d}$, which measure the level of import competition in the foreign and domestic markets, average 0.294 and 0.759 , respectively.

We obtain measures of model exchange rate exposure and pass-through for global firms using these inputs to evaluate equation (6) for each firm. We subsequently denote these estimates as model exposures. Summary statistics are provided in the last six rows of Table 5. The results indicate that the vast majority of firms have positive model exposures for reasonable

perform the analysis setting $\rho$ as low as 0.2 and the results are qualitatively similar. Other studies that provide estimates of product substitutability do not define the parameter in a comparable fashion, so it is not possible to make exact comparisons. 
values of $\rho_{f}$ and $\rho_{d}$ (i.e., 0.5, 0.7, and 0.9). This fact motivates our subsequent discussion of exposure in terms of levels instead of magnitudes. As suggested by Figure 2, a greater value of $\rho$ results in a larger magnitude of exposure. We note that both the predictions and estimates of the model are consistent with the results of Campa and Goldberg (1999) and Allayannis and Ihrig (2001) who document that exposures tend to be higher for more competitive industries. Examining the case when $\rho_{f}=\rho_{d}=0.7$ indicates that the average firm has a model exposure of 0.477 , yet some firms have negative model exposures. For this case, the largest model exposure is 1.577 .

While model exposures are mostly positive, they are typically smaller than those suggested by other theoretical models (e.g., the BDM model). Nonetheless, the model exposures are, on average, larger than the regression exposures estimated from equation (12) despite the fact that they already incorporate the effects of two hedging channels, pass-through and operational hedging. Recall from Table 3 that the regression exposures averaged 0.160 for the raw estimates and 0.090 for the unlevered estimates. Statistical tests (reported and discussed later) reject the model for producing exposure estimates that are too high. However, it is important to note that we have not adjusted the model exposures for any financial risk management undertaken by the firms.

The last three rows of Table 5 present the summary statistics for model pass-through estimates. Similar to the results for model exchange rate exposures, the global competition model allows for a wider range of values than the original BDM model. Firms have, on average, negative pass-through estimates. Consistent with the predictions of the model, the pass-through estimates decrease with product substitutability. While the mean and median values are negative, pass-through estimates are positive for more than the top quartile of firms.

\subsection{Analysis of Exposures from the Global Competition Model}

We further examine the theoretical exposures from the global competition model by splitting the sample along the calculated level of model exposure. This split might allow us to identify the role of other characteristics such as financial risk management and industry structure in determining foreign exchange rate exposure. Table 6 reports the results from this analysis. Values in Panel A show that that the spread between the calculated model exposure for high exposure (upper third) and low exposure (lower third) firms is about 0.7 , which is a sizeable 
difference. The regression exposures obtained from stock returns are smaller and the difference between the high and low exposure groups is not statistically different. ${ }^{25}$ This is true for both the raw and unlevered estimates and could be because the exposure estimates (from either the model or the regression method) are poor. Alternatively, the lower level of estimated exposures from stock returns could be the result of firms with high model exposures undertaking financial risk management or undertaking it to a greater extent. Our data on FC debt and FX derivatives use allows us to examine this alternative hypothesis.

In fact, the next two rows of Table 6 show that firms with high model exposure are both significantly more likely to have FC debt and to use FX derivatives. Specifically, $97.9 \%$ of firms with high model exposure have FC debt as compared to only $67.3 \%$ of firms with low model exposure. Similarly, $78.9 \%$ of firms with high model exposure use FX derivatives as compared to only $42.1 \%$ of firms with low model exposure. Both of these differences are significant at the 0.001 level.

We also relate the model exposures to the level of global competition in each firm's industry. Results for import penetration ratios reported in Table 6 reveal that firms with high model exposures face significantly higher global competition in their home market. In contrast, competition in the foreign market is similar for firms with high and low model exposures. We also analyze sales data for the WorldScope universe of manufacturing firms (which is considerably larger than our sample) and use these data to calculate a Herfindahl index as a measure of industry concentration, alternatively by global industry or by industry and country. A common assumption in the literature is that less concentrated industries are more competitive. Interestingly, there is no significant difference in global industry concentration. In fact, when we calculate Herfindahl indices for each country-industry combination, firms with high model exposure are in industries that are somewhat more concentrated than firms with low model exposure. These results indicate that local industry concentration is not (directly) related to our theoretical measure of foreign exchange rate exposure.

To further examine the role of financial hedging, Panel B of Table 6 reports mean values of model exposure and (unlevered) regression exposure by use of FX derivatives and FC debt.

\footnotetext{
${ }^{25}$ While we do not report results for the middle group, the values for these firms are much more like the high exposure group than the low exposure group for the regression exposures as well as the other characteristics.
} 
The results indicate that firms using FC debt, and especially firms using both FX derivatives and FC debt, have model exposures that are statistically greater than zero but regression exposures that are not different from zero. These results are consistent with firms using FC Debt (and FX derivatives) to reduce exposure.

Together, these results support the hypothesis that financial risk management plays an important role in explaining why the observed level of foreign exchange rate exposure for global firms is considerably less than theoretical predictions. We further examine this hypothesis by estimating regressions at the firm level to determine if the use of FC debt and FX derivatives is related to the difference between model exposures and regression exposures. Specifically, we estimate regressions of the following form

$$
\begin{aligned}
& \hat{\beta}_{F X, i}-\hat{\delta}_{i}=\alpha+\beta_{1} \text { FCDebt }_{i}+\varepsilon_{i} \\
& \hat{\beta}_{F X, i}-\hat{\delta}_{i}=\alpha+\beta_{2} \text { FXDerivatives }_{i}+\varepsilon_{i} \\
& \hat{\beta}_{F X, i}-\hat{\delta}_{i}=\alpha+\beta_{1} \text { FCDebt }_{i}+\beta_{2} \text { FXDerivatives }_{i}+\varepsilon_{i}
\end{aligned}
$$

where $\hat{\delta}$ is the calculated model exposure from equation (6), $\hat{\beta}_{F X}$ is the estimated, unlevered regression exposure from equation (12), FCDebt is a dummy variable for FC debt use, and FXDerivatives is a dummy variable for FX derivatives usage. If FC debt and FX derivatives are important for reducing foreign exchange rate exposure, then the coefficients $\beta_{1}$ and $\beta_{2}$ should be negative. ${ }^{26}$

Panel A of Table 7 shows results of estimating equations $(13 a-13 c)$ for various values of $\rho_{f}$ and $\rho_{d}$ using the full sample of firms. The first set of results confirms that the global competition model provides exposure estimates that are consistently too high (i.e., the model intercept is statistically negative). The next set of results, obtained by estimating equation (13a), shows that once controlling for a firm's use of FC debt, the global competition model cannot be rejected (i.e., the model intercept is not statistically different from zero). The coefficient

\footnotetext{
${ }^{26}$ To be precise, this is true (i) when model exposures are positive, or (ii) if we take the difference in absolute exposures when betas are estimated with a sufficiently high degree of precision. We chose not to specify the model in terms of differences in absolute values for two reasons. First, the vast majority (97\%) of our model exposures are positive. Second, regression exposures are not precise enough. In fact, by exploring examples with simulated data, we have determined that the tests from equations 13a-13c are preferred. Examining differences in absolute exposures tends to result in a surprisingly high probability of a type II error.
} 
estimates imply that firms with FC debt have about half the foreign exchange rate exposure of a firm without FC debt. Estimating equation (13b) shows that the use of FX derivatives also is related to lower exposure, but the coefficients are slightly smaller and the intercept is significantly less than zero. This suggests that FX derivatives significantly reduce exposure but cannot by themselves explain the difference between the regression exposure estimates and the model exposure estimates. The last part of Panel A shows results from estimating equation (13c). The coefficients on both FC debt and FX derivatives are negative, but for each variable the magnitudes decline to the extent that they are not statistically different from zero. Nonetheless, the combined estimates (and an F-test for the combined significance) show that financial hedging with both FC debt and FX derivatives reduces the gap between the regression exposure estimates and model exposure estimates to the degree that the difference (intercept) is not statistically significant.

The results in Panel A of Table 7 suggest that there may be important interaction effects between FC debt and FX derivatives. In fact, the pairwise Pearson correlation between the variables is 0.43 . This colinearity reduces the ability to distinguish between the risk reductions caused by each variable. Consequently, we also estimate regressions that control for various combinations of FC debt and FX derivatives use and are (by construction) orthogonal to each other. Specifically, we create new dummy variables for firms that i) use only FC debt only, ii) use FX derivatives only, and iii) use both FC debt and FX derivatives. The results are reported in Panel B of Table 7 and augment those from Panel A. As expected, we still observe that for all values of $\rho_{f}=\rho_{d}$ the intercepts are small and not statistically different from zero, indicating that the global competition model cannot be rejected. The largest (and only statistically significant) hedging effects are for firms that use both FC debt and FC derivatives suggesting that these two hedging methods are complements.

Overall, the results in Table 7 strongly support our hypothesis that corporations manage exchange rate risk via three distinct channels. First, firms pass part of exchange rate changes through to customers. Second, most global manufactures utilize some operational hedges. Both of these effects are captured by the global competition model estimates of exposure. Third, the regression results examining model error suggest corporations employ financial risk management 
strategies such as issuing FC debt and entering into FX derivatives transactions to reduce exposure.

\subsection{Exposure Attribution Analysis}

To assess the importance of these various forms of hedging, we evaluate equation (6) for different values of the parameters. The results of this analysis constitute a type of exposure attribution analysis for risk mitigation channels and are presented in Table 8. First, we set $\gamma_{f 1}=0$, $\gamma_{d 2}=1, \lambda_{f}=\lambda_{d}=0, \rho_{f}=\rho_{d}=(0.5,0.7,0.9)$, and other values at their sample means. This allows us to assess the exchange rate exposure of an atomistic firm without operational or financial hedges. In other words, we calculate exposure for an otherwise typical firm with no market power (and thus limited ability to pass-through exchange rate changes), no foreign assets, and no FC debt or FX derivatives. The values for exchange rate exposures range from 0.581 to 0.769 as $\rho_{f}=\rho_{d}$ varies from 0.5 to 0.9 . These exposure values are relatively large and, as expected, increase with the level of product substitutability.

The second row of Table 8 provides estimates of the reduction in exposure due to the pass-through channel by setting $\lambda_{f}=0.294$ and $\lambda_{d}=0.759$ (the sample averages). The results indicate that pass-through reduces exposure for our typical firm by $16.2 \%$ when product substitutability is relatively low $\left(\rho_{f}=\rho_{d}=0.5\right)$ and only $9.6 \%$ when product substitutability is relatively high $\left(\rho_{f}=\rho_{d}=0.9\right)$. Intuitively, greater product market competition from similar goods reduces the potential to pass through exchange rate movements to customers.

To assess the marginal effect of operational hedging for a typical firm, the third row of Table 8 shows exposure values for a firm with the average level of foreign assets, $\gamma_{f l}=0.191$ and $\gamma_{d 2}=0.809$. The results suggest that matching the currency of costs and revenues results in a reduction of exposure between $8.7 \%$ and $16.1 \%$. Interestingly, the effect of operational hedges increases with product substitutability so that the combined reduction in exposure from both channels is relatively constant (around 25\%) for the typical firm.

The results in Table 7 suggest that financial hedging and in particular the use of FC debt has a significant effect on exchange rate exposure. To estimate the relative importance of financial hedging, we subtract the estimated coefficient for firms using both FC debt and FX derivatives (Panel B of Table 7) from the previous exposure estimates. The fourth row of Table 8 shows that a relatively large reduction in exposure (equivalent to $42.9 \%$ to $46.5 \%$ of the base- 
case exposure) can be attributed to financial hedging. Altogether, these estimates suggest that a typical firm employing all three channels of risk mitigation will reduce its overall exchange rate exposure by about $70 \%$ to levels very close to the median unlevered regression exposure estimates (reported in the last row). We also note that the reduction in exposure is not highly dependent of the level of product market competition as measured by the product substitutability parameters. Thus, firms may be able to make up for hedging opportunities not available to them from one channel by hedging more via other channels so as to achieve a preferred level of final exposure.

To further explore the relation between different hedging channels at the firm level, we conduct a similar type of attribution analysis with firm-specific parameter estimates. In particular, we attribute firm-level exposure reduction from pass-through by taking the difference in model exposures between the no hedging case $\left(\lambda_{f}=\lambda_{d}=0, \gamma_{f 1}=0, \gamma_{d 2}=1\right.$, and no financial hedging) and the pass-through only case ( $\lambda_{f}$ and $\lambda_{d}$ set to actual values, $\gamma_{f 1}=0, \gamma_{d 2}=1$, and no financial hedging). Similarly, we attribute firm-level exposure reduction from operational hedging by taking the difference in model exposures between the pass-through only case and the both pass-through and operational hedging case $\left(\lambda_{f}, \lambda_{d}, \gamma_{f l}\right.$, and $\gamma_{d 2}$ set to actual values, $\gamma_{f l}=0, \gamma_{d 2}$ $=1$, and no financial hedging).

Average reductions in exposure (not tabulated) are very similar to those reported for hypothetical firms in Table 8. For example, for $\rho_{f}=\rho_{d}=0.7$ pass-through reduces exposure by an average of $14.0 \%$ and operational hedging reduces exposure by an average of $14.1 \%$. As suggested by the results in Table 8 , the estimated exposure attributed to pass-through is significantly negatively correlated with operational hedging $(-0.43)$ and financial hedging with both FC debt and FX derivatives (-0.18). However, there is a significant positive correlation between operational hedging and financial hedging exposure reductions $(0.15)$. These suggest that pass-through is a substitute for other types of hedging. Or equivalently, that when industry structure (which is largely out of the direct control of management) prevents firms from passing through exchange rate fluctuations to prices, firms compensate by increasing operational and financial hedging. The complementary relation between the operational and financial hedging channels is consistent with the results of Kedia and Mozumdar (2003). Using a sample of U.S. firms, they document a significant association between a firm having foreign operations and its use of FC debt. 
We also examine each of the hedging channels by generating scatter-plots of exposure as a function of firm characteristics. We group firms by industry and plot points for the 26 industries with available data for at least 10 firms. Panel A of Figure 3 shows the strong negative relationship between pass-through and exposure ( $\mathrm{R}^{2}$ of an OLS regression equals 0.75 ). This relationship highlights that firms with high exposure also tend to have large (negative) passthrough. Pass-through is determined in part by the level of import competition. Panel B shows the expected positive relationship between exposure and foreign import competition, but the relationship is not as strong as one might expect $\left(\mathrm{R}^{2}=0.19\right)$ given the robust relationship in Panel A.

Panel C shows a positive relationship between exposure and foreign assets at the industry level. This contrasts with the results for an individual firm (e.g., Panel B of Figure 2) where foreign assets reduce exposure, ceteris paribus. These results again demonstrate that firms with more foreign assets are likely to have higher exposure (e.g., because they typically have more foreign sales) and that operational hedges provide only a partial hedge for exchange rate movements. Nonetheless, the observed relationship between exposure and foreign assets is also weak $\left(\mathrm{R}^{2}=0.15\right)$. These loose relations for foreign import penetration and foreign assets are quite surprising because the values for the global competition model exposure estimates are mechanically related to these variables. The results highlight the diversity of exposures and risk management methods across industries.

Panel D of Figure 3 reveals a strong positive relationship between the use of FC debt or FX derivatives and BDM model exposure $\left(\mathrm{R}^{2}=0.54\right)$. The plot confirms that industries with high FX exposures as a result of their operations are more likely to undertake financial risk management. We stress that these variables are not related via the global competition model.

\subsection{Additional Factors}

It is somewhat surprising that the estimates for exposure reduction are so large for financial hedging. There are several potential explanations for this result. First, financial hedges are a relatively inexpensive method of reducing foreign exchange exposure so they might be preferred to more costly alternatives such as relocating production facilities. Likewise, financial hedging might simply be the available technique if alternatives are not feasible (e.g., as our results suggest, industry structure may not allow for significant pass-through). Alternatively, our 
empirical method may identify other types of unobserved exposure mitigation techniques as part of financial hedging if those methods are correlated with the use of FC debt or FX derivatives. These might include dynamically adjusting other financial variables under the control of managers, the use of alternative risk transfer tools, negotiations with suppliers and customers on terms (e.g., currency) of transactions, etc.

An even more serious concern is that systematic errors in the regression or model exposure estimates, as well as industry-level or country-level factors coincidentally related to FC debt or FX derivatives usage, could lead to spurious estimates for the degree of financial hedging. The analysis to this point has relied heavily on the assumptions of the global competition model accurately characterizing firms' foreign exchange exposure. However, other factors not explicitly modeled might be important for determining foreign exchange rate exposure and thus might explain the differences between the model and regression exposures. If other factors were consistently important, this might suggest that the theoretical model or the ad hoc analysis of financial hedging is not a sufficiently complete model of exchange rate exposure. Finally, the regression exposures are estimated with varying degrees of accuracy. So, it is possible that firm-level estimation error in $\beta_{F X}$ correlated with FC debt or FX derivative usage could lead to a spurious estimate of the importance of financial hedging.

We examine these issues by estimating a set of alternative models to the ones reported in Table 7. We concentrate on alternatives to the specification reported in Panel B of Table 7 with $\rho_{f}=\rho_{d}=0.7$ though the conclusions are similar for different specifications (e.g., other values of $\rho_{f}$ and $\rho_{d}$ ). Table 9 reports the results of this analysis. The first column repeats the values shown in Table 7 for comparison. The second column shows the same specification but weights observations by the inverse of the estimated standard error for $\beta_{F X}$ in equation (12). The results are similar. The coefficient on the dummy variable for both FC debt and FX derivatives remains negative and significant though it is somewhat smaller in magnitude. The intercept is closer to zero and remains statistically insignificant, and the adjusted $\mathrm{R}^{2}$ of the model increases slightly. Together, these two facts suggest that weighting observations improves the quality of the model slightly.

The next column expands the model to include as explanatory variables firm size, profitability (gross profit margin), tangible assets, line-of-business diversification (number of 
business segments), debt maturity, a dividend payout dummy variable, firm liquidity (current ratio), as well as country and industry dummy variables. ${ }^{27}$ The findings indicate that other firm characteristics are not generally significant determinants of residual foreign exchange rate exposure. The exception is the positive relation for the dividend payout dummy variable which indicates that model exposures are lower than regression exposures for dividend paying firms. However, other results indicate that the global competition model still can explain FX exposures (i.e., intercept is still zero) and that financial hedging is still associated with a significant decrease in the difference between the regression exposures and model exposures. In fact, the use of only FX derivatives becomes statistically significant along with the use of both FC debt and FX derivatives. However, it is no longer possible to interpret the coefficient on the financial hedging variables as equivalent to the change in exposure, because the other factors included in the model are not orthogonal to the financial hedging variables. The next column reports results from the same specification where observations are weighted by the inverse of the estimated standard error for $\beta_{F X}$. The results in this case are comparable, but model fit improves.

\subsection{Are the Financial Hedging Results Reliable?}

Taken together, the results in Table 9 provide generally consistent evidence that financial hedging reduces exchange rate exposure. While these results are statistically significant, it cannot be determined from the analysis if the implied values for the magnitude of financial hedging are realistic. Furthermore, with only binary hedging variables, we lack information about the magnitudes of the hedging effects which potentially lowers the power of our tests. In this section, we use two methods to examine the reliability of these results. First, we discuss a simulation analysis to determine the power of tests with only binary variables for FX derivatives and FC debt. Second, we attempt to compare the implied magnitude of financial hedging with estimates for the amount of FC debt and FX derivatives a typical firm actually uses.

To see if our results and conclusions are likely to be the result of type I errors, we conduct a simulation analysis where we generate 1,000 random samples with general properties very similar to our sample. Specifically, we set the number of observations in each of the four

\footnotetext{
${ }^{27}$ These characteristics are not available for all firms which reduces the sample size to 969 firms.
} 
hedging categories (and therefore the total number of observations) to match our sample. We generate the following random variables:

- $\quad \beta \sim N(0.09,1.62)$

- $\delta$ (no hedge $) \sim N(0.060,0.16)$

- $\delta$ (FX Derivatives only) $\sim N(0.103,0.16)$

- $\delta$ (FC Debt only) $\sim(0.378,0.16)$

- $\delta$ (Both FX Derivatives and FC Debt) $\sim N(0.543,0.16)$

where $\sim N(\mu, \sigma)$ represents a normally distributed variable with mean $\mu$ and standard deviation $\sigma$. Note that we assume the $\delta$ s also are measured with error (equal to about half the standard deviation of $\delta$ s in our sample). By construction, hedging will reduce exposure, and the question is if we can detect this with our tests.

We estimate regressions such as those reported in Table 7, Panel B. ${ }^{28}$ Overall, the results indicate that our tests do have power to identify the effect of financial hedging on exposures. In particular, when the model includes only an intercept, we reject the model $100 \%$ of the time (i.e., the intercept is always significantly negative). When we include the hedging variables, the median intercept is 0.027 with a standard deviation of 0.496 and we fail to reject the model with hedging at the 5\% level in all cases (there are no type I errors). The distribution of estimated coefficients shows that our ability to detect hedgers varies by type of hedger. Specifically, we have little power to identify 'FX Derivatives Only' hedgers as significantly reducing exposure (median $p$-value is 0.483). We have some power to identify 'FC Debt Only' hedgers as significantly reducing exposure (median $p$-value is 0.066). We have high power to identify 'Both FX Derivatives and FC Debt' hedgers as significantly reducing exposure (median $p$-value is 0.002). Consequently, these simulation results are consistent with the regression results reported in the paper as well as our interpretation and conclusions for FC debt. However, we cannot reliably determine if firms using just FX derivatives are able to reduce risk.

The question remains as to whether or not the implied magnitudes of financial hedging are realistic. Ideally we would like to conduct our analysis in the previous section with the levels of FX derivatives and FC debt, but the sparse reporting of exact amounts of FC debt and FX derivatives makes this impossible for our full sample. Instead, we search a random sample of

\footnotetext{
${ }^{28}$ For brevity we do not table the results, but all results are available on request from the authors.
} 
annual reports and other public databases until we obtain reliable estimates of the amount of FC debt for 50 firms. As an estimate for the extent of hedging with FX derivatives, we rely on values obtained by Guay and Kothari (2003) for a sample of 143 U.S. nonfinancial firms using FX derivatives.

We first repeat the analysis reported in Table 8 for only firms that use FC debt or FX derivatives. Table 10 provides summary statistics for these firms and compares them to the full sample of firms. Financial hedgers tend to have a larger market capitalization, higher leverage, and total debt (including preferred stock). Based on the sample of $50 \mathrm{FC}$ debt users, the percent of FC debt is $46.3 \%$.

Using the estimated model parameters for financial hedgers, we evaluate the base case, pass-through and operational hedging exposures in the same way as for the results reported in Table 8. The results are shown in Table 10 and reveal that financial hedgers have somewhat higher base exposures as well as higher exposures after pass-through and operational hedging. However, the marginal changes in FX exposure for financial hedgers through these channels are similar to the reductions for all firms. Next, we calculate the effects on FX exposure of financial hedging using the regression method estimates reported in Table 7. These lead to a typical reduction in exposure of $42.7 \%$ which is very similar to the $42.9 \%$ decrease in exposure due to financial hedging for the full sample of firms.

To calculate rough estimates of the direct effects of financial hedging on exposure, we assume that a $1 \%$ appreciation of the trade-weighted local currency index value:

1. decreases the value of total debt by $1 \%$ of the book value of FC debt and therefore increases the value of equity by the same amount, and

2. increases the mark-to-market value of FX derivatives by $1 \%$ of the notional principal which will also increase the value of equity by the same amount. ${ }^{29}$

\footnotetext{
${ }^{29}$ More specifically, we assume that the notional principal outstanding for the typical firm using FX derivatives is $\$ 517.4$ million (from Guay and Kothari, 2003, Table 2, page 433). This amount may be too high because the average market value of derivative users in their sample is $\$ 8,571$ compared to $\$ 6,205$ in our sample. On the other hand, this amount may be too low because their data are for 1997 and derivative use by nonfinancial firms has been increasing over time. The relation between mark-to-market and exchange rate changes assumes that the delta of the portfolio is -1.0 when it is likely to be somewhat larger due to the use of options. In the Guay and Kothari (2003)
} 
The results for the FC debt estimates and FX derivative estimates are reported separately at the bottom of Table 10. The findings suggest that for a typical financial hedger FC debt reduces base case exposure by about $25.4 \%$ and FX derivatives reduce FX exposure by about $11.5 \%$. Together, they reduce FX exposure by $36.9 \%$ to 0.266 . While these more direct estimates suggest less reduction from financial hedging then was implied by the regression model estimates, the values indicate that the results provided in Table 7 are certainly feasible. Furthermore, the exposures after financial hedging from either method are similar to the median unlevered regression exposures obtained from estimating equation (12). Finally, we note that the relative magnitudes for FX derivatives and FC debt are different though the sum is similar. This may be because, as noted above, our tests lack power for isolating the effects of FX derivatives.

A final concern regarding our global sample is the assumption that foreign sales and foreign assets are directly related to FX exposure and hedging for firms in the European Monetary Union (EMU). In at least some cases, the measures we use include foreign sales and assets in other EMU countries that would not lead to any direct FX exposure or hedge. By chance, our sample only includes 44 firms from EMU countries so the effects on the results are likely to be small. To verify this conjecture we conduct all of the analysis excluding these 44 firms and find that the conclusions are unchanged. ${ }^{30}$

\section{Conclusions}

Previous studies have examined in detail independent channels that give rise to exchange rate exposure, but little academic research has investigated the interrelationships between these

sample, only about $25 \%$ of FX derivatives are options, so the delta of the overall derivatives portfolio should be close to -1.0 if most options are near the money.

${ }^{30}$ Specifically, regression results that exclude firms in the European Monetary Union (EMU) have almost identical coefficients as those reported in Tables 6 and 7. Results like those presented in Table 9 are similar except for the last column where the coefficient on the FX-derivatives-only dummy variable is larger in magnitude (more negative and significant at the $5 \%$ level), and the coefficient on the current ratio becomes positive and significant at the $1 \%$ confidence level. Comparing the 44 EMU firms to the rest of the sample reveals that country regression exposures are significantly higher but about as volatile, that these firms have more foreign sales and assets, and that they are more likely to have FC debt and use FX derivatives. In addition, import penetration is somewhat higher for EMU firms. All of these differences are consistent with these firms having greater exposures but doing more operational and financial hedging. 
determinants. For example, the associations between exchange rate exposure, product market competition, and corporate risk management are not well understood. This paper takes a step toward filling this gap by examining these relations for a global sample of non-financial companies. Specifically, we assume corporate financial managers can use pricing policies, operational hedging (e.g., international allocation of production costs), and financial hedging strategies in order to mitigate the effects of currency fluctuations. Moreover, these decisions are not made under the assumption that the firm operates in isolation, but rather after a detailed analysis of the industry's situation and the actions of industry peers. Thus, by reflecting the broader economic context the firm is operating in and the nature of competition it is facing, firmlevel decisions make foreign exchange exposure endogenous.

Our primary results suggest that each of the three channels for mitigating exchange rate exposure is likely to be important for our sample of large global manufacturing firms. Exchange rate pass-through and operational hedging are each responsible for about a $10 \%$ to $15 \%$ reduction in exposure, and financial risk management accounts for about another $37 \%$ to $43 \%$ decrease in exposure relative to a hypothetical firm that cannot mitigate exposure at all. Altogether, firms reduce their gross exchange rate exposure by about $70 \%$ via the three channels to levels measured from equity prices. Consequently, our analysis suggests that the relatively weak foreign exchange rate exposure, which has been considered a puzzle by some, is to be expected once accounting for all the relevant factors. In particular, firms implicitly appear aware of their gross exposures and adjust their operations and financing activities. Our results point to a need for further research examining the precise role of financial risk management in globally competitive corporations. $^{31}$

Overall, our study contributes to the literature in several ways. First, we take a more comprehensive approach to studying exchange rate exposure. For example, the model we derive allows for global firms in an imperfectly competitive global market. Second, our sample of firms using financial risk management to mitigate exchange rate exposure is among the largest

\footnotetext{
31 While our global competition model allows for the empirical examination of a richer set of firms, we do not attempt to explicitly model the interaction between financial hedging and product market competition for our global firm. Similarly, we treat our global firm as having independently operating foreign and domestic divisions when in reality there may exist important interactions between local and foreign markets not captured by our extension of the BDM model. However, some existing research (e.g., Adam, Dasgupta, and Titman, 2007, Mello and Ruckes, 2005) develops theoretical models of financial risk management in imperfectly competitive markets.
} 
examined to date. Finally, and most importantly, we are able to shed light on a puzzle in financial economics by carefully decomposing the close relationship between theoretical and observed foreign exchange rate exposures. 


\section{References}

Adam, T., S. Dasgupta, and S. Titman, 2007, Financial constraints, competition and hedging in industry equilibrium, Journal of Finance 62(5), 2329 - 2366.

Adler, M. and B. Dumas, 1984, Exposure to currency risk: Definition and measurement, Financial Management 13, 41-50.

Allayannis, G., G. Brown, and L. Klapper, 2003, Capital structure and financial risk: Evidence from foreign debt use in East Asia, Journal of Finance 58(6), 2667-2709.

Allayannis, G., and J. Ihrig, 2001, Exposure and markups, Review of Financial Studies 14(3), 805-835.

Allayannis, G., J. Ihrig, and J.P. Weston, 2001, Exchange-rate hedging: Financial versus operational strategies, The American Economic Review 91(2), 391-395.

Allayannis, G., and E. Ofek, 2001, Exchange rates exposure, hedging, and the use of foreign currency derivatives, Journal of International Money and Finance 20, 273-296.

Amihud, Y., 1993, Evidence on exchange rates and the valuation of equity shares. In Amihud, Y., and R. Levich (eds.), Exchange Rates and Corporate Performance. Business One, Irwin, IL.

Bartov, E., G.M. Bodnar, and A. Kaul, 1996, Exchange rate variability and the riskiness of U.S. multinational firms: evidence from the breakdown of the Bretton Woods system, Journal of Financial Economics 42(1), 105-132.

Bartram, S.M., 2004, Linear and nonlinear foreign exchange rate exposures of German nonfinancial corporations, Journal of International Money and Finance 23(4), 673-699.

Bartram, S.M., and G.A. Karolyi, 2006, The impact of the introduction of the Euro on foreign exchange rate risk exposures, Journal of Empirical Finance 13 (4-5), 519-549.

Bodnar, G.M., and W.M. Gentry, 1993, Exchange rate exposure and industry characteristics: Evidence from Canada, Japan, and the USA, Journal of International Money and Finance 12(1), 29-45.

Bodnar, G.M., B. Dumas, and R.C. Marston, 2002, Pass-through and exposure, Journal of Finance 57(1), 199-231.

Bodnar, G.M., and R.C. Marston, 2002, Exchange rate exposure: A simple model, in Global Risk Management: Financial, Operational and Insurance Strategies, J. Choi and M. Power (eds), International Finance Review 3, (Elsevier Science: JAI), 107-116.

Bodnar, G.M., and M.H. Wong, 2003, Estimating exchange rate exposures: Issues in model structure, Financial Management 32(1), 35-67.

Brown, G., P. Crabb, and D. Haushalter, 2006, Are firms successful at selective hedging? Journal of Business 79(6), 2925-2949.

Campa J. and L. Goldberg, 1999, Investment, pass-through and exchange rates: A cross-country comparison, International Economic Review 40, 287-314. 
Carrieri, F., V. Errunza, and B. Majerbi, 2006, Does emerging market exchange risk affect global equity prices? Journal of Financial and Quantitative Analysis 41, 511-540.

Carter, D., C. Pantzalis, and B. Simkins, 2003, Asymmetric exposure to foreign-exchange risk: Financial and real options implemented by US multinationals, University of Oklahoma Working Paper.

Choi, J. and A. Prasad, 1995, Exchange rate sensitivity and its determinants: a firm and industry analysis of US multinationals, Financial Management 24, 77-88.

Chow, E.H., W.Y. Lee, and M.E. Solt, 1997, The exchange-rate risk exposure of asset returns, Journal of Business 70(1), 105-123.

Chowdhry, B., and J. Howe, 1999, Corporate risk management for multinational corporations: Financial and operational hedging policies, European Finance Review 2, 229-246.

Dahlquist, M. and G. Robertsson, 2001, Exchange rate exposures, risk premia and firm characteristics, Duke University Working Paper.

De Santis, G., and B. Gerard, 1998. How big is the premium for currency risk? Journal of Financial Economics 49, 375-412.

Dekle, R., 2005, Exchange rate exposures and foreign market competition: Evidence from Japanes firms, Journal of Business 78, 281-299.

Doidge, C., J. Griffin and R. Williamson, 2006, Measuring the economic importance of exchange rate exposure, Journal of Empirical Finance 13, 550-576.

Dominguez, K. and L. Tesar, 2001, A re-examination of exchange rate exposure, American Economic Review 91(2), 396-399.

Dominguez, K. and L. Tesar, 2006, Exchange rate exposure, Journal of International Economics $68,188-218$.

Dumas, D., and M. Solnik, 1995, The world price of foreign exchange risk. Journal of Finance 50, 445-479.

Flood, E., and D. Lessard, 1986, On the measurement of operating exposure to exchange rates: A conceptual approach, Financial Management (Spring), 25-37.

Francis, B., I Hasan, and D. Hunter, 2008, Can hedging tell the full story? Reconciling differences in U.S. aggregate- and industry-level exchange rate risk premium, Journal of Financial Economics, forthcoming.

Graham, J., and C. Harvey, 2001, The theory and practice of corporate finance: Evidence from the field, Journal of Financial Economics 60(2-3), 187-243.

Griffin, J.M., and R.M. Stulz, 2001, International competition and exchange rate shocks: A Cross-country industry analysis of stock returns, Review of Financial Studies 14(1), 215241.

Guay, W., and S.P. Kothari, 2003. How much do firms hedge with derivatives? Journal of Financial Economics 70, 423-461. 
Hagelin N. and B. Pramborg, 2004, Hedging foreign exchange exposure: Risk reduction from transaction and translation hedge, Journal of International Financial Management and Accounting 15, 1-20.

He J. and L. K. Ng, 1998, The foreign exchange exposure of Japanese multinational firms, Journal of Finance 53, 733-54.

Hekman, C., 1985, A financial model of foreign exchange exposure, Journal of International Business Studies (Summer), 83-99.

Hung, J., 1992, Assessing the exchange rate's impact on U.S. manufacturing profits. Quarterly Review, Federal Reserve Bank of New York, Winter, 44-63.

Jorion, P. 1990, The exchange-rate exposure of U.S. multinationals, Journal of Business 63, 331345.

Jorion, P., 1991, The pricing of exchange rate risk in the stock market. Journal of Financial and Quantitative Analysis 64, 363-376.

Kedia, S. and A. Mozumdar, 2003, Foreign currency-denominated debt: an empirical examination, Journal of Business 76, 521-546.

Mello, A, J. Parsons, and A. Triantis, 1995, An integrated model of multinational flexibility and financial hedging, International Economic Review 39, 27-51.

Mello, A., and M. Ruckes, 2005, Financial hedging and product market rivalry, University of Wisconsin working paper.

Marston, R., 2001, The effects of industry structure on economic exposure, Journal of International Money and Finance 20, 149-164.

Nain, A., 2004, The strategic motives for corporate risk management, University of Michigan working paper.

Opler, T., L. Pinkowitz, R. Stulz, and R. Williamson, 1999, The determinants and implications of corporate cash holdings, Journal of Financial Economics 51, 3-46.

Pantzalis, C., B. Simkins, and P. Laux, 2001, Operational hedges and the foreign exchange exposure of U.S. multinational corporations, Journal of International Business Studies $32,793-812$.

Parsley, D. and H. Popper, 2006, Exchange rate pegs and exchange rate exposures in East Asia, Journal of International Money and Finance 25(6), 992-1009.

Petersen, M.A. and S.R. Thiagarajan, 2000, Risk measurement and hedging: With and without derivatives, Financial Management 29(4), 5-30.

Pringle J. and R. Conolly, 1993, The nature and causes of foreign currency exposures, Journal of Applied Corporate Finance 6, 61-72.

Shapiro, A., 1975, Exchange rate changes, inflation, and the value of the multinational corporation, Journal of Finance 30(2), 485-502. 
Simkins, B. and P. Laux, 1996, Derivative use and the exchange rate risk of large U.S. corporations, Conference Proceedings: The Second International Finance Conference, Georgia Tech University.

Starks, L.T. and K.D. Wei, 2006, Foreign exchange rate exposure and short-term cash flow sensitivity, University of Texas working paper.

Triantis, A., 2000, Real options and corporate risk management, Journal of Applied Corporate Finance 13(2), 64-73.

von Ungern-Sternberg, T., and C. von Weizsäcker, 1990, Strategic foreign exchange management, Journal of Industrial Economics 38, 381-395.

Williamson, R., 2001, Exchange rate exposure and competition: evidence from the automotive industry, Journal of Financial Economics 59(3), 441-475.

Wong, F., 2000, The association between SFAS no. 119 derivatives disclosures and foreign exchange risk exposure of manufacturing firms, Journal of Accounting Research 38, 387417. 


\section{Appendix A. Derivation of Foreign Exchange Rate Exposure}

\section{A.1 The Exporting Firm}

For the derivation of the exposure of the exporter, "foreign" always refers to the country of firm 2 (the foreign, import-competing firm) and "domestic" always refers to the country of firm 1 (the exporter). The exposure of a firm that produces domestically and abroad, but sells all of its output abroad (exporter) under quantity competition is derived as follows. Profits of the exporter in its domestic currency are defined as

$$
\pi_{1}^{*}=S P_{1} X_{1}-\left(C_{1}^{*}+S C_{1}\right) X_{1}
$$

and the cost ratio in domestic currency as

$$
R=\frac{C_{2}^{*}+S C_{2}}{C_{1}^{*}+S C_{1}} .
$$

Substituting for equilibrium price $\left(P_{1}\right)$ and quantity $\left(X_{1}\right)$ yields

$$
\begin{aligned}
& \pi_{1}^{*}=S \frac{C_{1}^{*}+S C_{1}}{S \rho_{f}\left(1-\lambda_{f}\right)} \cdot \lambda_{f} Y \frac{S \rho_{f}\left(1-\lambda_{f}\right)}{\left(C_{1}^{*}+S C_{1}\right)}-\left(C_{1}^{*}+S C_{1}\right) \cdot \lambda_{f} Y \frac{S \rho_{f}\left(1-\lambda_{f}\right)}{\left(C_{1}^{*}+S C_{1}\right)} \\
&=S \lambda_{f} Y-\lambda_{f} Y S \rho_{f}(1-\lambda) \\
&=S \lambda_{f} Y\left[1-\rho_{f}\left(1-\lambda_{f}\right)\right] \\
& \ln \pi_{1}^{*}=\ln S+\ln \lambda_{f}+\ln Y+\ln \left[1-\rho_{f}\left(1-\lambda_{f}\right)\right] .
\end{aligned}
$$

Differentiating with respect to the natural logarithm of the exchange rate (in domestic currency relative to foreign currency) yields

$$
\begin{aligned}
\frac{d \ln \pi^{*}}{d \ln S} & =1+\frac{d \ln \lambda_{f}}{d \ln S}+\frac{d}{d \ln S}\left[1-\rho_{f}\left(1-\lambda_{f}\right)\right] \\
& =1+\frac{d \ln \lambda_{f}}{d \ln S}+\frac{\rho_{f} \lambda_{f}}{1-\rho_{f}\left(1-\lambda_{f}\right)} \cdot \frac{d \ln \lambda_{f}}{d \ln S} \\
& =1+\left[1+\frac{\rho_{f} \lambda_{f}}{1-\rho_{f}\left(1-\lambda_{f}\right)}\right] \cdot \frac{d \ln \lambda_{f}}{d \ln S} \\
& =1+\left(1-\lambda_{f}\right) \rho_{f}\left[\left(1-\gamma_{f 1}\right) \gamma_{f 2}-\gamma_{f 1}\left(1-\gamma_{f 2}\right)\right]+\frac{\left(1-\lambda_{f}\right) \lambda_{f} \rho_{f}^{2}\left[\left(1-\gamma_{f 1}\right) \gamma_{f 2}-\gamma_{f 1}\left(1-\gamma_{f 2}\right)\right]}{1-\rho_{f}\left(1-\lambda_{f}\right)}
\end{aligned}
$$


where $\gamma_{f 1}=\frac{S C_{1}}{C_{1}^{*}+S C_{1}}$ and $\gamma_{f 2}=\frac{S C_{2}}{C_{2}^{*}+S C_{2}}$. The derivation of $\frac{d \ln \lambda_{f}}{d \ln S}$ is available on request.

We define:

- $\lambda_{f}$ is the market share of the exporting firm in the foreign market.

- $\quad \gamma_{f 1}$ is the exporter's share of cost in foreign currency (due to foreign currency inputs or foreign production).

- $\quad \gamma_{f 2}$ is the import-competing firm's share of cost in foreign currency (note, this is basically the fraction of cost in "local" currency for the import-competing firm and thus equal to one in the BDM model, where the import-competing firm only produces in its local market).

\section{A.2 The Import-Competing Firm}

We derive the exposure of the import-competing firm by first keeping the setting of the BDM model, and subsequently adjusting for the need to consider an import-competing firm in the country of the exporter in order to be able to combine both into one global firm. We begin by defining profits of the import-competing firm in its domestic currency ${ }^{32}$ as

$$
\pi_{2}=P_{2} X_{2}-\left(\frac{C_{2}^{*}}{S}+C_{2}\right) X_{2}
$$

and the cost ratio as

$$
R=\frac{C_{2}^{*}+S C_{2}}{C_{1}^{*}+S C_{1}}
$$

Substituting for equilibrium price $\left(P_{2}\right)$ and quantity $\left(X_{2}\right)$ yields

\footnotetext{
${ }^{32}$ The exchange rate is defined as in the above derivation for the exporter
} 


$$
\begin{aligned}
\pi_{2} & =\frac{C_{2}+\frac{C_{2}^{*}}{S}}{\rho_{f} \lambda_{f}} \cdot \frac{\left(1-\lambda_{f}\right) Y \rho_{f} \lambda_{f}}{C_{2}+\frac{C_{2}^{*}}{S}}-\left(C_{2}+\frac{C_{2}^{*}}{S}\right) \cdot \frac{\left(1-\lambda_{f}\right) Y \rho_{f} \lambda_{f}}{C_{2}+\frac{C_{2}^{*}}{S}} \\
& =\left(1-\lambda_{f}\right) Y-\left(1-\lambda_{f}\right) Y \rho_{f} \lambda_{f} \\
& =\left(1-\lambda_{f}\right) Y\left(1-\rho_{f} \lambda_{f}\right) \\
\ln \pi_{2} & =\ln \left(1-\lambda_{f}\right)+\ln Y+\ln \left(1-\rho_{f} \lambda_{f}\right) .
\end{aligned}
$$

Differentiating with respect to the natural logarithm of the exchange rate yields

$$
\begin{aligned}
\frac{d \ln \pi_{2}}{d \ln S} & =\frac{d \ln \left(1-\lambda_{f}\right)}{d \ln S}+\frac{d \ln \left(1-\rho_{f} \lambda_{f}\right)}{d \ln S} \\
& =\frac{1}{1-\lambda_{f}} \cdot \frac{d\left(1-\lambda_{f}\right)}{d \ln S}+\frac{1}{1-\rho_{f} \lambda_{f}} \cdot \frac{d\left(1-\rho_{f} \lambda_{f}\right)}{d \ln S} \\
& =\frac{-1}{1-\lambda_{f}} \cdot \frac{d \lambda_{f}}{d \ln S}-\frac{\rho_{f}}{1-\rho_{f} \lambda_{f}} \cdot \frac{d \lambda_{f}}{d \ln S} \\
& =\frac{-1}{1-\lambda_{f}} \cdot \lambda_{f} \cdot\left(1-\lambda_{f}\right) \rho_{f}\left[\left(1-\gamma_{f 1}\right) \gamma_{f 2}-\gamma_{f 1}\left(1-\gamma_{f 2}\right)\right]-\frac{\rho_{f}}{1-\rho_{f} \lambda_{f}} \cdot \lambda_{f} \cdot\left(1-\lambda_{f}\right) \rho_{f}\left[\left(1-\gamma_{f 1}\right) \gamma_{f 2}-\gamma_{f 1}\left(1-\gamma_{f 2}\right)\right] \\
& =-\lambda_{f} \rho_{f}\left[\left(1-\gamma_{f 1}\right) \gamma_{f 2}-\gamma_{f 1}\left(1-\gamma_{f 2}\right)\right]-\frac{\left(1-\lambda_{f}\right) \lambda_{f} \rho_{f}^{2}\left[\left(1-\gamma_{f 1}\right) \gamma_{f 2}-\gamma_{f 1}\left(1-\gamma_{f 2}\right)\right]}{1-\rho_{f} \lambda_{f}}
\end{aligned}
$$

where

$\gamma_{f 1}=\frac{S C_{1}}{C_{1}^{*}+S C_{1}}$ and $\gamma_{f 2}=\frac{S C_{2}}{C_{2}^{*}+S C_{2}}$

We note that the import-competing firm has no transaction exposure from domestic sales, thus there is no leading " 1 " in the exposure equation as for the exporter.

\section{A.3 The Global Firm}

Total exchange rate exposure for the global firm $(\delta)$ is defined as the foreign sales-weighted average of exchange rate exposures from foreign operations $\left(\delta_{f}\right)$ and domestic operations $\left(\delta_{d}\right)$ so that

$$
\delta=\phi \delta_{f}+(1-\phi) \delta_{d} .
$$


In particular, we interpret the exposure from foreign operations $\left(\delta_{f}\right)$ as the exposure of a firm that produces domestically and abroad, but sells all of its output abroad (exporter). Similarly, we interpret the exposure from domestic operations $\left(\delta_{d}\right)$ as the exposure of a firm that produces domestically and abroad, but sells all of its output at home (import-competing firm).

While we can take the exposure of the exporter as derived above, we need to consider an import-competing firm located in the country of the exporter, in order to be able to combine both to form the global firm. In other words, we wish to analyze an import-competing firm but from the currency perspective of the exporting firm above, in order to have the same currency perspective. This is equivalent to examining an import-competing firm located in the country of the exporter. Thus, this remains the exposure of a firm that produces domestically and abroad, but sells all of its output domestically (import-competing firm) under quantity competition. In order to be able to combine the exposure of the exporter with that of the import-competing firm, we need to make the following adjustments to the above exposure of the import-competing firm:

- The sign of the exposure has to be changed since the currency perspective is opposite.

- $\left(1-\lambda_{f}\right)$ is the market share of the import-competing firm in the foreign market. Therefore, we replace this with $\lambda_{d}$ which we define as the market share of the import-competing firm in its local market.

- Replace $\rho_{f}$ with $\rho_{d}$.

- $\quad \gamma_{f 1}$ is the exporter's share of cost in foreign currency (due to foreign currency inputs or foreign production). We replace $\gamma_{f 1}$ with $\gamma_{d 1}$, which is the fraction of domestic cost of foreign firms exporting into the local market and the fraction of domestic cost of local competing firms.

- $\quad \gamma_{f 2}$ is the import-competing firm's share of cost in foreign currency. We replace $\gamma_{f 2}$ with $\gamma_{d 2}$, which is the fraction of domestic cost of the import-competing firm.

Consequently,

$$
\delta_{d}=\left(1-\lambda_{d}\right) \rho_{d}\left[\left(1-\gamma_{d 1}\right) \gamma_{d 2}-\gamma_{d 1}\left(1-\gamma_{d 2}\right)\right]+\frac{\left(1-\lambda_{d}\right) \lambda_{d} \rho_{d}^{2}\left[\left(1-\gamma_{d 1}\right) \gamma_{d 2}-\gamma_{d 1}\left(1-\gamma_{d 2}\right)\right]}{1-\rho_{d}\left(1-\lambda_{d}\right)},
$$

thus 


$$
\begin{aligned}
& \delta=\phi\left[1+\left(1-\lambda_{f}\right) \rho_{f}\left[\left(1-\gamma_{f 1}\right) \gamma_{f 2}-\gamma_{f 1}\left(1-\gamma_{f 2}\right)\right]+\frac{\left(1-\lambda_{f}\right) \lambda_{f} \rho_{f}^{2}\left[\left(1-\gamma_{f 1}\right) \gamma_{f 2}-\gamma_{f 1}\left(1-\gamma_{f 2}\right)\right]}{1-\rho_{f}\left(1-\lambda_{f}\right)}\right] \\
& +(1-\phi)\left[\left(1-\lambda_{d}\right) \rho_{d}\left[\left(1-\gamma_{d 1}\right) \gamma_{d 2}-\gamma_{d 1}\left(1-\gamma_{d 2}\right)\right]+\frac{\left(1-\lambda_{d}\right) \lambda_{d} \rho_{d}^{2}\left[\left(1-\gamma_{d 1}\right) \gamma_{d 2}-\gamma_{d 1}\left(1-\gamma_{d 2}\right)\right]}{1-\rho_{d}\left(1-\lambda_{d}\right)}\right] \\
& \delta=\phi\left[1+\left(1-\lambda_{f}\right) \rho_{f} \mu_{f}+\frac{\left.\left(1-\lambda_{f}\right) \lambda_{f} \rho_{f}^{2} \mu_{f}\right]+(1-\phi)\left[\left(1-\lambda_{f}\right) \rho_{d} \mu_{d}+\frac{\left(1-\lambda_{f}\right) \lambda_{d} \rho_{d}^{2} \mu_{d}}{\left.1-\rho_{d}\left(1-\lambda_{d}\right)\right]}\right.}{\text { with }}\right. \\
& \mu_{f}=\left[\left(1-\gamma_{f 1}\right) \gamma_{f 2}-\gamma_{f 1}\left(1-\gamma_{f 2}\right)\right] \\
& \text { and } \\
& \mu_{d}=\left[\left(1-\gamma_{d 1}\right) \gamma_{d 2}-\gamma_{d 1}\left(1-\gamma_{d 2}\right)\right]
\end{aligned}
$$

In order to recover the exposure of the exporter in the original BDM model, set $\phi=1$ and $\left(1-\gamma_{f 2}\right)=0$, i.e. $\gamma_{f 2}=1$, which indicates that the import-competing firm has costs only in the foreign country (i.e., its local market). Similarly, in order to obtain the exposure of the importcompeting firm in the BDM model, set $\phi=0$ and $\left(1-\gamma_{f 2}\right)=0$, i.e. $\gamma_{f 2}=1$, which indicates that the import-competing firm has costs only in the foreign country (i.e., its local market). 


\section{Appendix B. Derivation of Foreign Exchange Rate Pass-Through}

\section{B.1 The Exporting Firm}

For the derivation of the pass-through of the exporter, "foreign" always refers to the country of firm 2 (the foreign, import-competing firm) and "domestic" always refers to the country of firm 1 (the exporter). We derive pass-through of a firm that produces domestically and abroad, but sells all of its output abroad (exporter) under quantity competition. Pass-through is the derivative of output price with regards to the exchange rate. Differentiating the output price of the exporter $\left(P_{1}\right)$ with respect to the natural logarithm of the exchange rate (in domestic currency relative to foreign currency) yields

$$
\begin{aligned}
& \frac{d \ln \mathrm{P}_{1}}{d \ln S}=\frac{d \ln }{d \ln S}\left[\frac{C_{1}^{*}+S C_{1}}{S \rho_{f}\left(1-\lambda_{f}\right)}\right]=\frac{S \rho_{f}\left(1-\lambda_{f}\right)}{C_{1}^{*}+S C_{1}} \cdot \frac{d}{d \ln S}\left[\frac{C_{1}^{*}+S C_{1}}{S \rho_{f}\left(1-\lambda_{f}\right)}\right] \\
& =\frac{S \rho_{f}\left(1-\lambda_{f}\right)}{C_{1}^{*}+S C_{1}} \cdot \frac{d}{d \ln S}\left[\frac{C_{1}^{*}+e^{\ln S} C_{1}}{e^{\ln S} \rho_{f}\left(1-\lambda_{f}\right)}\right] \\
& =\frac{S \rho_{f}\left(1-\lambda_{f}\right)}{C_{1}^{*}+S C_{1}} \cdot\left[\frac{S C_{1} S \rho_{f}\left(1-\lambda_{f}\right)-\left(C_{1}^{*}+S C_{1}\right) \cdot \frac{d}{d \ln S}\left[S \rho_{f}\left(1-\lambda_{f}\right)\right]}{S^{2} \rho_{f}^{2}\left(1-\lambda_{f}\right)^{2}}\right] \\
& =\frac{S \rho_{f}\left(1-\lambda_{f}\right)}{C_{1}^{*}+S C_{1}} \cdot \frac{S C_{1} S \rho_{f}\left(1-\lambda_{f}\right)}{S^{2} \rho_{f}^{2}\left(1-\lambda_{f}\right)^{2}}-\frac{S \rho_{f}\left(1-\lambda_{f}\right)}{C_{1}^{*}+S C_{1}} \cdot \frac{\left(C_{1}^{*}+S C_{1}\right) \cdot \frac{d}{d \ln S}\left[S \rho_{f}\left(1-\lambda_{f}\right)\right]}{S^{2} \rho_{f}^{2}\left(1-\lambda_{f}\right)^{2}} \\
& =\frac{S C_{1}}{C_{1}^{*}+S C_{1}}-\frac{\frac{d}{d \ln S}\left[S \rho_{f}\left(1-\lambda_{f}\right)\right]}{S \rho_{f}\left(1-\lambda_{f}\right)}=\gamma_{f 1}-\frac{1}{S \rho_{f}\left(1-\lambda_{f}\right)} \cdot \frac{d\left[e^{\ln S} \rho_{f}\left(1-\lambda_{f}\right)\right]}{d \ln S} \\
& =\gamma_{f 1}-\frac{1}{S \rho_{f}\left(1-\lambda_{f}\right)} \cdot\left[S \rho_{f}\left(1-\lambda_{f}\right)+S \rho_{f} \frac{d\left(1-\lambda_{f}\right)}{d \ln S}\right] \\
& =\gamma_{f 1}-\frac{1}{S \rho_{f}\left(1-\lambda_{f}\right)} \cdot\left[S \rho_{f}\left(1-\lambda_{f}\right)-S \rho_{f} \frac{d \lambda_{f}}{d \ln S}\right] \\
& =\gamma_{f 1}-\frac{1}{S \rho_{f}\left(1-\lambda_{f}\right)} \cdot\left[S \rho_{f}\left(1-\lambda_{f}\right)-S \rho_{f} \cdot \lambda_{f} \cdot\left(1-\lambda_{f}\right) \rho_{f} \cdot\left[\left(1-\gamma_{f 1}\right) \gamma_{f 2}-\gamma_{f 1}\left(1-\gamma_{f 2}\right)\right]\right] \\
& =\left(\gamma_{f 1}-1\right)+\lambda_{f} \rho_{f}\left[\left(1-\gamma_{f 1}\right) \gamma_{f 2}-\gamma_{f 1}\left(1-\gamma_{f 2}\right)\right]
\end{aligned}
$$




\section{B.2 The Import-Competing Firm}

We derive the pass-through by first keeping the setting of the original BDM model, and subsequently adjusting for the need to consider an import-competing firm in the country of the exporter in order to be able to combine both into one global firm. Pass-through is the derivative of output price with regards to the exchange rate. Differentiating the output price of the importcompeting firm $\left(P_{2}\right)$ with respect to the natural logarithm of the exchange rate (defined as above in foreign currency relative to domestic currency from the perspective of the exporter) yields

$$
\begin{aligned}
& \frac{d \ln \mathrm{P}_{2}}{d \ln S}=\frac{d \ln }{d \ln S}\left[\frac{\frac{C_{2}^{*}}{S}+C_{2}}{\rho_{f} \lambda_{f}}\right]=\frac{\rho_{f} \lambda_{f}}{\frac{C_{2}^{*}}{S}+C_{2}} \frac{d}{d \ln S}\left[\frac{\frac{C_{2}^{*}}{S}+C_{2}}{\rho_{f} \lambda_{f}}\right] \\
& =\frac{\rho_{f} \lambda_{f}}{\frac{C_{2}^{*}}{S}+C_{2}} \frac{d}{d \ln S}\left[\frac{C_{2}^{*} e^{-\ln S}+C_{2}}{\rho_{f} \lambda_{f}}\right] \\
& =\frac{\rho_{f} \lambda_{f}}{\frac{C_{2}^{*}}{S}+C_{2}}\left[\frac{\frac{-C_{2}^{*} \rho_{f} \lambda_{f}}{S}-\left(\frac{C_{2}^{*}}{S}+C_{2}\right) \frac{d}{d \ln S}\left[\rho_{f} \lambda_{f}\right]}{\rho_{f}^{2} \lambda_{f}^{2}}\right] \\
& =\frac{\rho_{f} \lambda_{f}}{\frac{C_{2}^{*}}{S}+C_{2}} \cdot \frac{\frac{-C_{2}^{*} \rho_{f} \lambda_{f}}{S}}{\rho_{f}^{2} \lambda_{f}^{2}}-\left[\frac{\rho_{f} \lambda_{f}}{\frac{C_{2}^{*}}{S}+C_{2}} \cdot \frac{\frac{C_{2}^{*}}{S}+C_{2}}{\rho_{f}^{2} \lambda_{f}^{2}} \cdot \rho_{f} \cdot \frac{d \lambda_{f}}{d \ln S}\right] \\
& =\frac{1}{\frac{C_{2}^{*}}{S}+C_{2}} \cdot \frac{\frac{-C_{2}^{*} \rho_{f} \lambda_{f}}{S}}{\rho_{f} \lambda_{f}}-\left[\frac{1}{\lambda_{f}} \cdot \frac{d \lambda_{f}}{d \ln S}\right] \\
& =\frac{-C_{2}^{*}}{C_{2}^{*}+S C_{2}}-\frac{1}{\lambda_{f}} \cdot \lambda_{f} \cdot\left(1-\lambda_{f}\right) \rho_{f} \cdot\left[\left(1-\gamma_{f 1}\right) \gamma_{f 2}-\gamma_{f 1}\left(1-\gamma_{f 2}\right)\right] \\
& =-\left(1-\gamma_{f 2}\right)-\left(1-\lambda_{f}\right) \rho_{f}\left[\left(1-\gamma_{f 1}\right) \gamma_{f 2}-\gamma_{f 1}\left(1-\gamma_{f 2}\right)\right]
\end{aligned}
$$

\section{B.3 The Global Firm}

Total pass-through for the global firm $(\eta)$ is defined as the foreign sales-weighted average of pass-through from foreign operations $\left(\eta_{f}\right)$ and domestic operations $\left(\eta_{d}\right)$ so that

$$
\eta=\phi \eta_{f}+(1-\phi) \eta_{d}
$$


In particular, we interpret the pass-through from foreign operations $\left(\eta_{f}\right)$ as the pass-through of a firm that produces domestically and abroad, but sells all of its output abroad (exporter). Similarly, we interpret the pass-through from domestic operations $\left(\eta_{d}\right)$ as the pass-through of a firm that produces domestically and abroad, but sells all of its output at home (import-competing firm).

As was the case when deriving the exposure of the global firm, we can take the passthrough of the exporter as derived above, but we need to consider an import-competing firm located in the country of the exporter, in order to be able to combine both to form the global firm. Consequently, we make the same changes in variables described in Appendix A.3. This results in

$$
\eta_{d}=\left(1-\gamma_{d 2}\right)+\lambda_{d} \rho_{d}\left[\left(1-\gamma_{d 1}\right) \gamma_{d 2}-\gamma_{d 1}\left(1-\gamma_{d 2}\right)\right]
$$

and therefore

$$
\begin{aligned}
\eta & =\phi\left[\left(\gamma_{f 1}-1\right)+\lambda_{f} \rho_{f}\left[\left(1-\gamma_{f 1}\right) \gamma_{f 2}-\gamma_{f 1}\left(1-\gamma_{f 2}\right)\right]\right] \\
& +(1-\phi)\left[\left(1-\gamma_{d 2}\right)+\lambda_{d} \rho_{d}\left[\left(1-\gamma_{d 1}\right) \gamma_{d 2}-\gamma_{d 1}\left(1-\gamma_{d 2}\right)\right]\right]
\end{aligned}
$$

so that

$$
\begin{aligned}
\eta & =\phi\left[\left(\gamma_{f 1}-1\right)+\lambda_{f} \rho_{f} \mu_{f}\right]+(1-\phi)\left[\left(1-\gamma_{d 2}\right)+\lambda_{d} \rho_{d} \mu_{d}\right] \\
& \text { with } \\
\mu_{f}= & {\left[\left(1-\gamma_{f 1}\right) \gamma_{f 2}-\gamma_{f 1}\left(1-\gamma_{f 2}\right)\right] } \\
& \text { and } \\
\mu_{d}= & {\left[\left(1-\gamma_{d 1}\right) \gamma_{d 2}-\gamma_{d 1}\left(1-\gamma_{d 2}\right)\right] }
\end{aligned}
$$

In order to obtain the pass-through of the exporter in the original BDM model, set $\phi=1$ and $\left(1-\gamma_{f 2}\right)=0$, i.e. $\gamma_{f 2}=1$, which means that the import-competing firm has costs only in the foreign country (i.e., its local market). Similarly, in order to obtain the pass-through of the import-competing firm in the BDM model, set $\phi=0$ and $\left(1-\gamma_{f 2}\right)=0$, i.e. $\gamma_{f 2}=1$, which means that the import-competing firm has only cost in the foreign country (i.e., its local market). 


\section{Figure 1: Feasible Exposures of BDM Model and Global Competition Model}

The figure shows feasible exposures $(\delta)$ of the BDM model and the global competition model as a function of the degree of product substitutability $\left(\rho_{f}=\rho_{d}\right)$. Exposures decline toward zero when product substitutability declines, because firms will pass through more of exchange rate changes to customers by adjusting prices. Absolute exposures reach their maximums when the product market is perfectly competitive $\left(\rho_{f}=\rho_{d}=1\right)$.

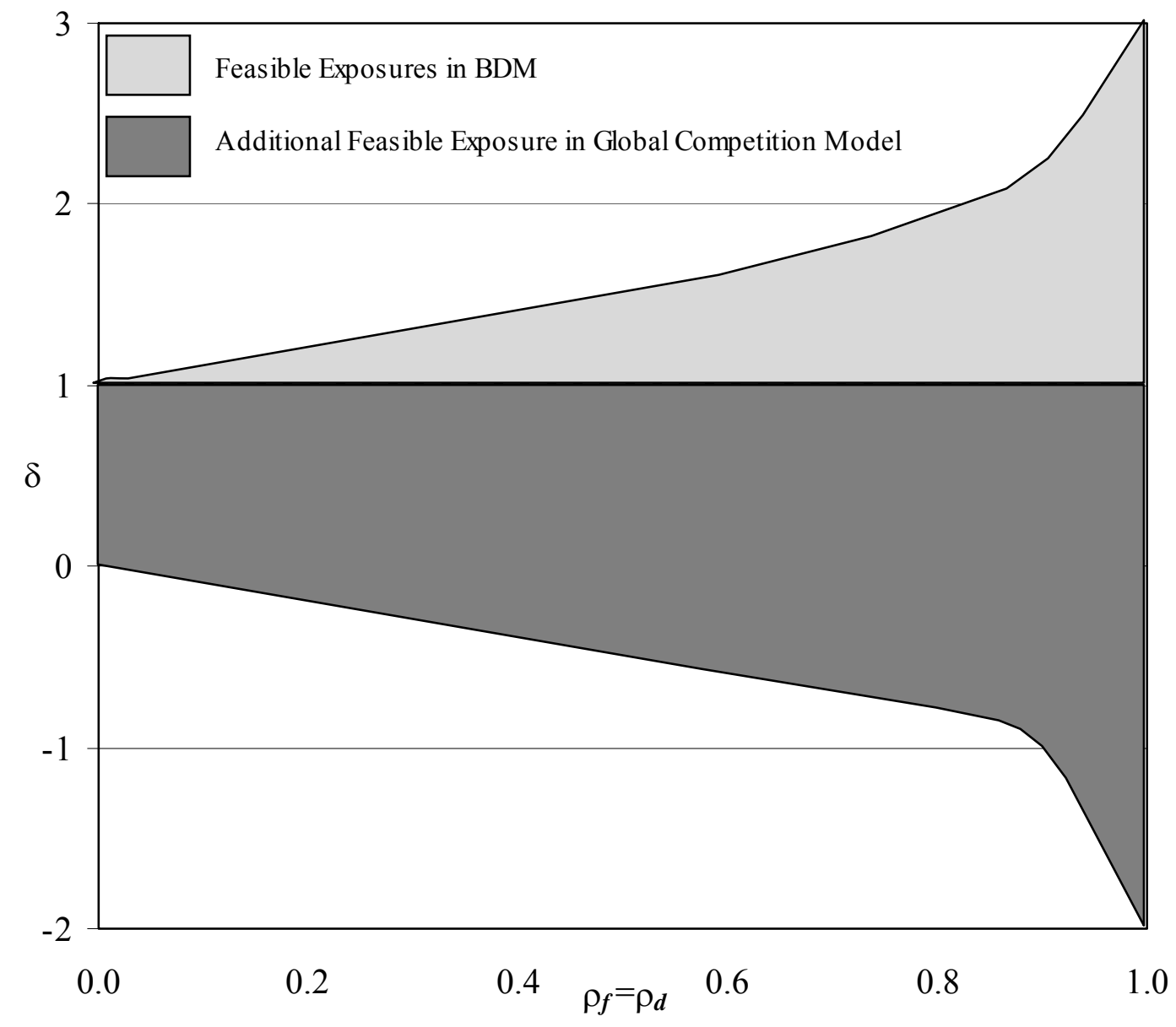


Figure 2: Comparative Static Analysis for Global Competition Model Exposure

The figures plot exchange rate exposure values $(\delta)$ obtained from the global competition model for various input parameter values. Parameter values for all variables except the one plotted on the horizontal axis are set to $\phi_{f}=0.5$, $\gamma_{f 1}=0.3, \gamma_{d l}=0.6, \gamma_{f 2}=0.6, \rho_{f}=\rho_{d}=0.7, \lambda_{f}=0.3$, and $\lambda_{d}=0.7$.

Panel A

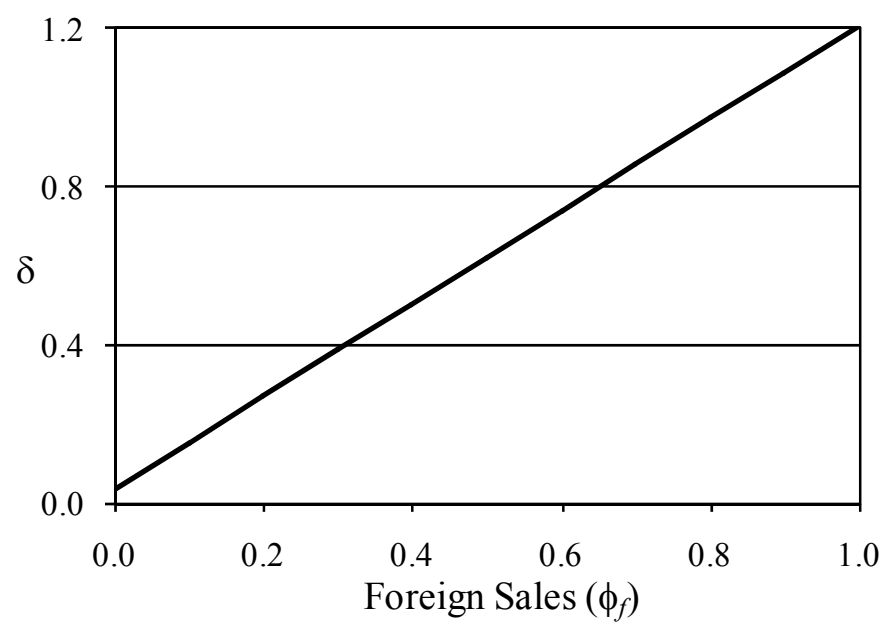

Panel C

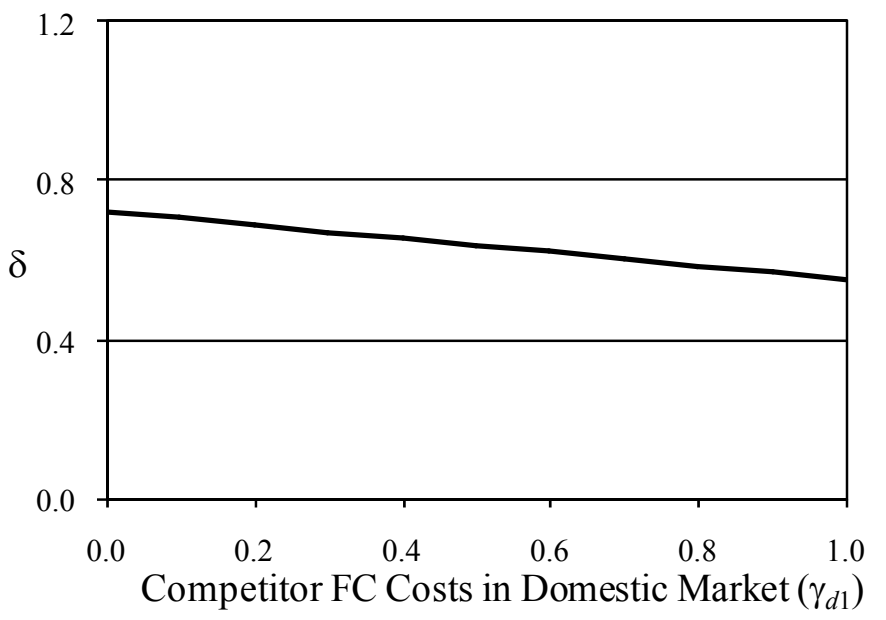

Panel E

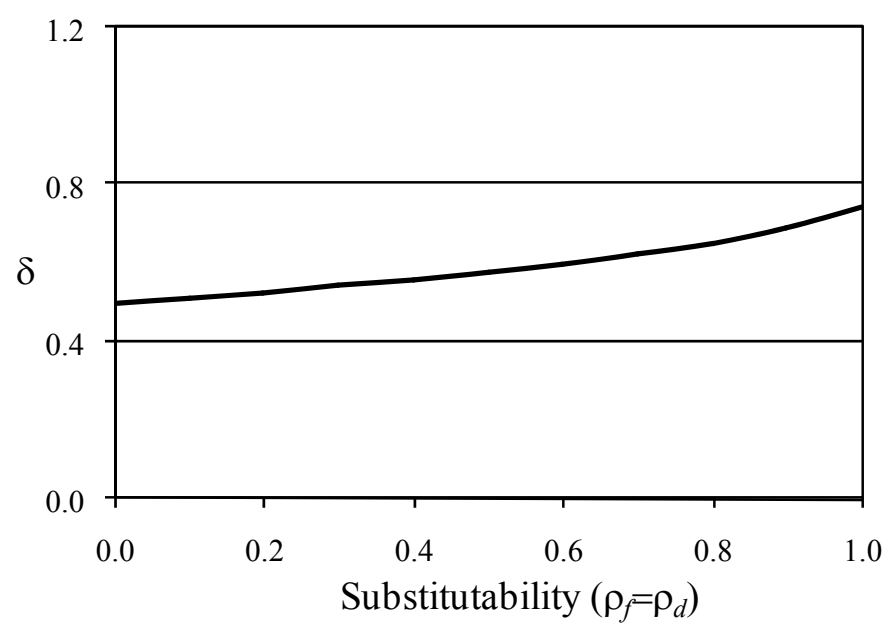

Panel B

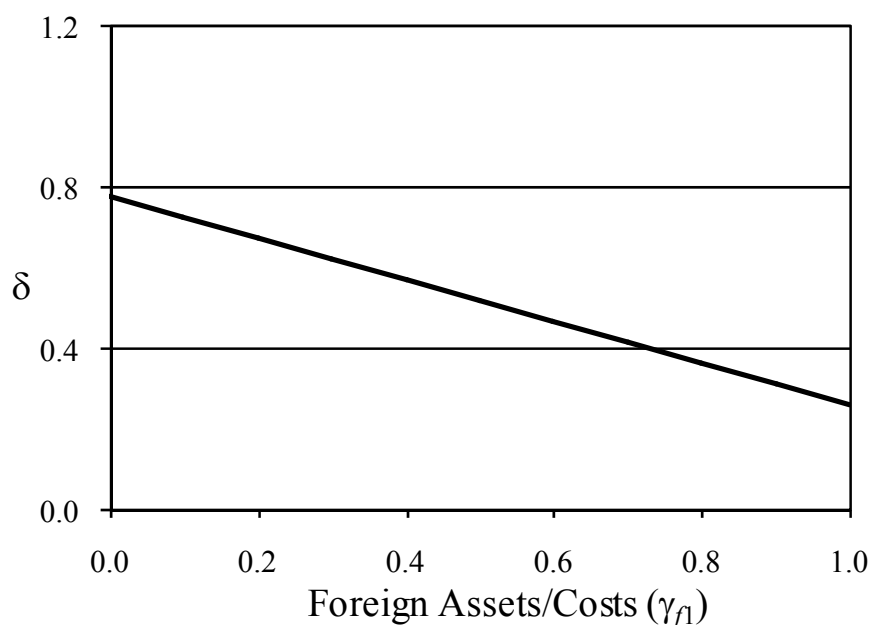

Panel D

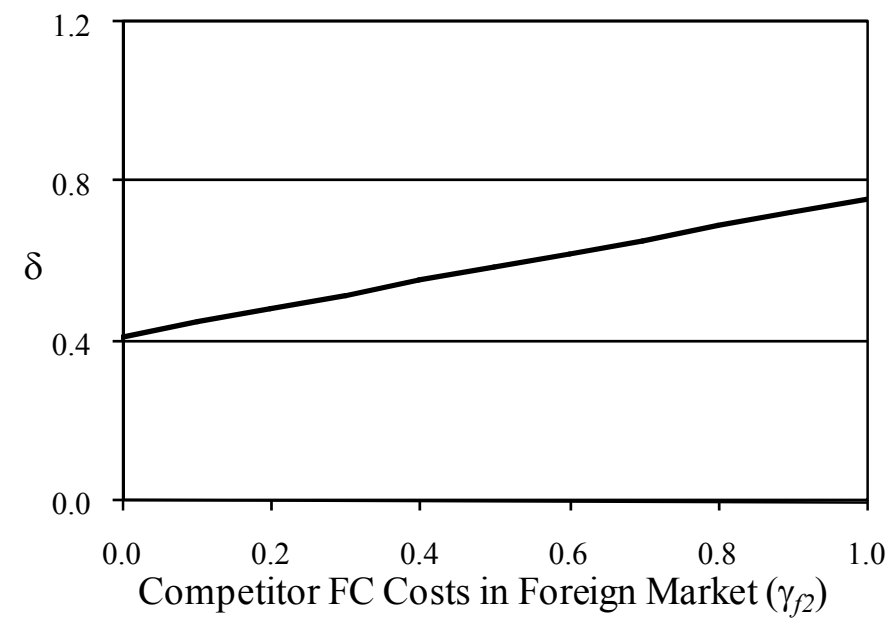

Panel F

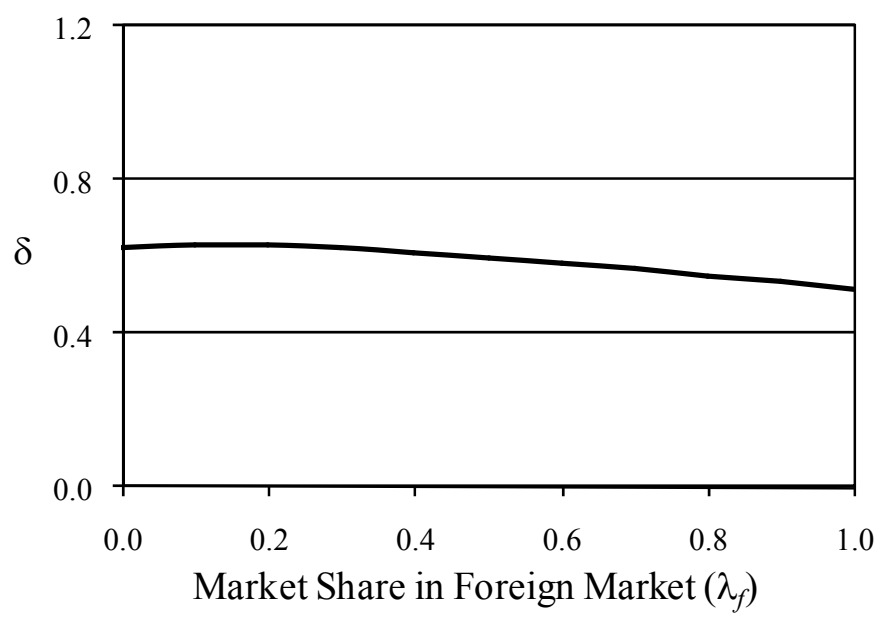


Figure 3: Exposure Estimates from the Global Competition Model by Industry

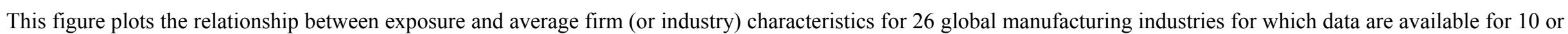
mor firms. Detailed descriptions of each variable are provided in the main text and in Table A1 in the appendix.

Panel A

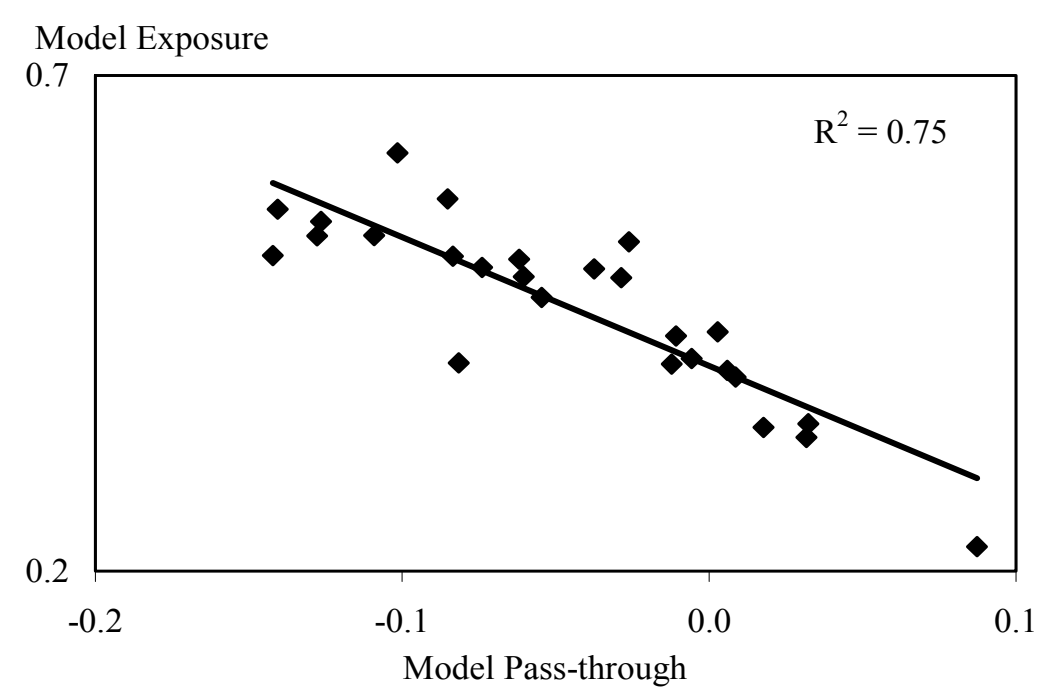

Panel C

Model Exposure

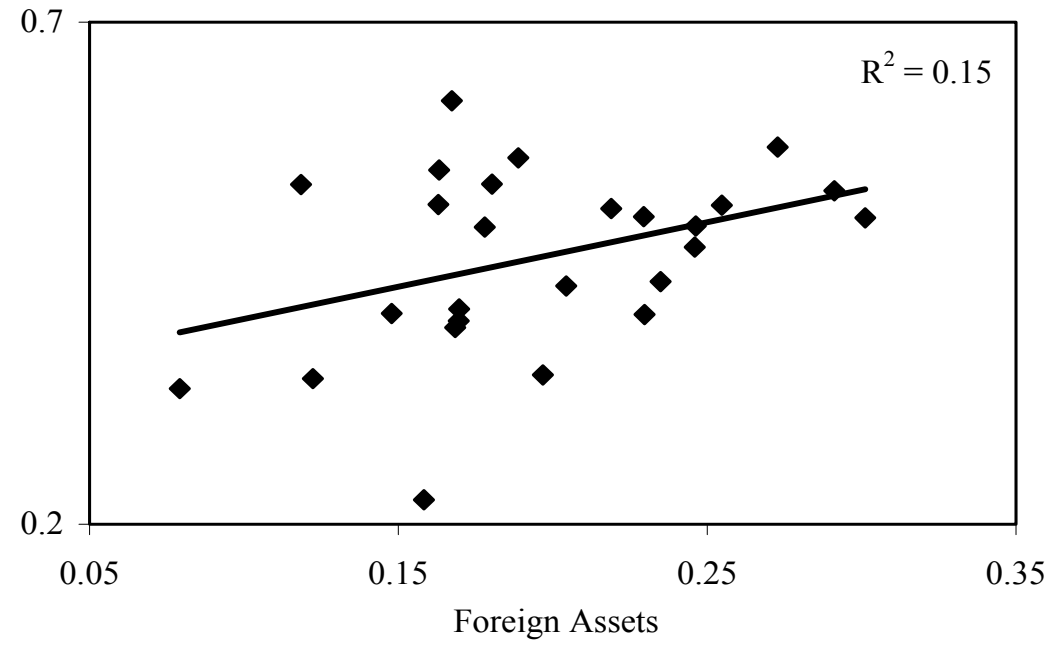

Panel B

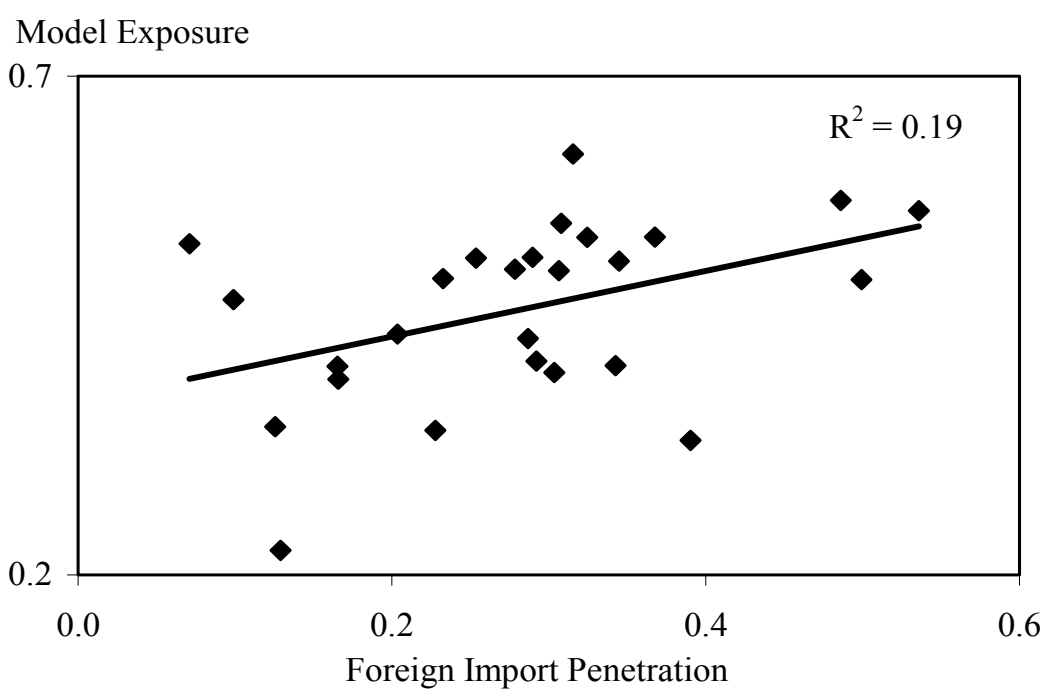

Panel D

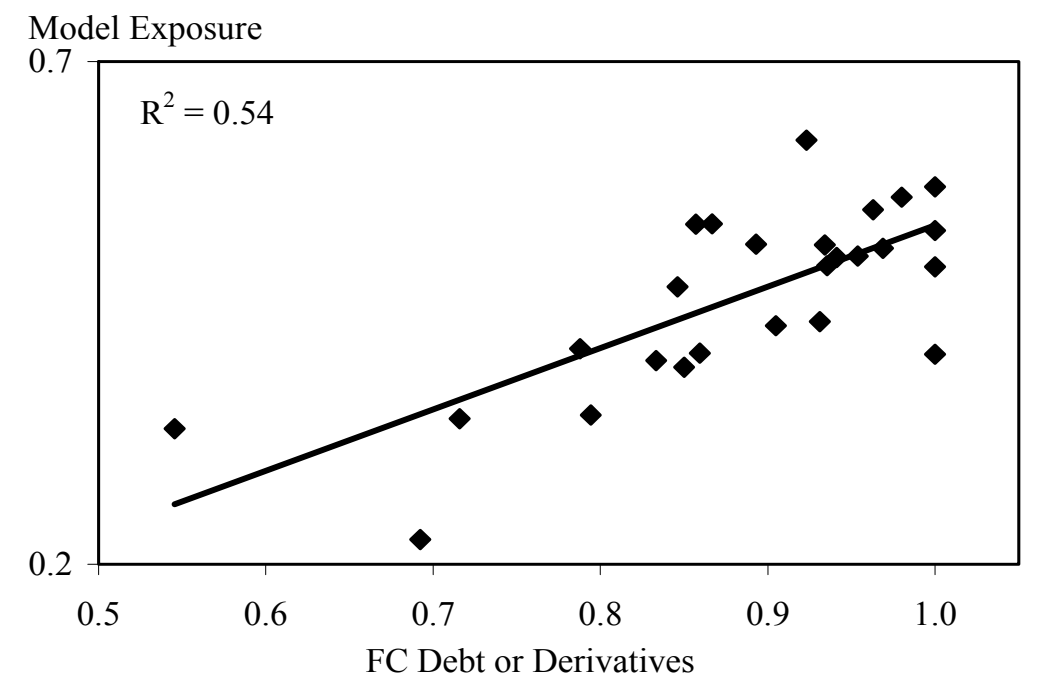




\section{Table 1: Theoretical and Empirical Foreign Exchange Rate Exposures of Automotive Companies}

The table shows relevant firm characteristics and resulting theoretical foreign exchange rate exposures based on the model by Bodnar and Marston (2002), as well as estimated foreign exchange rate exposures. In particular, the columns show (from left to right) the name of the firm, the percentage of foreign sales (from WRDS), the Gross Profit Margin (3-year average), the resulting Gross Exposure, the percentage of foreign production (from WARDS), the resulting Model Exposure, the notional amount of foreign exchange rate derivatives relative to firm value (FX Derivatives), a proxy of the hedging effect of foreign currency debt relative to firm value (Foreign Currency Debt), and the resulting Residual Exposure. The last columns of the table show the foreign exchange rate exposure estimated from regressions of the excess return on the local stock market index and the trade-weighted exchange rate index on the excess stock return of automotive companies, adjusted for leverage (Regression Exposure), and the corresponding $p$-value (in brackets). All exchange rates are defined in local currency relative to (a basket of) foreign currency. Exposure regressions are estimated using weekly data in local currency for the period 2000 to 2004.

\begin{tabular}{|c|c|c|c|c|c|c|c|c|c|c|}
\hline \multirow[b]{2}{*}{ Company } & \multirow[b]{2}{*}{$\begin{array}{c}\text { Foreign } \\
\text { Sales }\end{array}$} & \multirow[b]{2}{*}{$\begin{array}{c}\text { Gross } \\
\text { Profit } \\
\text { Margin } \\
\end{array}$} & \multirow[b]{2}{*}{$\begin{array}{c}\text { Gross } \\
\text { Exposure }\end{array}$} & \multirow[b]{2}{*}{$\begin{array}{c}\text { Foreign } \\
\text { Production }\end{array}$} & \multirow[b]{2}{*}{$\begin{array}{c}\text { Model } \\
\text { Exposure }\end{array}$} & \multicolumn{2}{|c|}{ Financial Hedging } & \multirow[b]{2}{*}{$\begin{array}{l}\text { Residual } \\
\text { Exposure } \\
\end{array}$} & \multirow[b]{2}{*}{$\begin{array}{c}\text { Regression } \\
\text { Exposure }\end{array}$} & \multirow[b]{2}{*}{$p$-value } \\
\hline & & & & & & $\begin{array}{c}\mathrm{FX} \\
\text { Derivatives }\end{array}$ & $\begin{array}{c}\text { Foreign } \\
\text { Currency } \\
\text { Debt }\end{array}$ & & & \\
\hline Ford & 0.44 & 0.22 & 1.99 & 0.53 & 0.14 & 0.04 & 0.02 & 0.08 & -0.50 & 0.12 \\
\hline General Motors & 0.41 & 0.21 & 1.93 & 0.53 & -0.04 & 0.18 & 0.12 & -0.34 & -0.30 & 0.20 \\
\hline Hyundai & 0.60 & 0.20 & 3.03 & 0.07 & 2.74 & 0.18 & 0.15 & 2.41 & 0.03 & 0.76 \\
\hline Honda & 0.74 & 0.31 & 2.41 & 0.60 & 1.07 & 0.15 & 0.04 & 0.88 & 0.90 & $<0.01$ \\
\hline Isuzu & 0.72 & 0.15 & 4.84 & 0.44 & 2.34 & 0.49 & 0.15 & 1.70 & 0.07 & 0.39 \\
\hline Mazda & 0.70 & 0.23 & 3.10 & 0.20 & 2.43 & 0.15 & 0.09 & 2.18 & 0.20 & 0.14 \\
\hline Mitsubishi & 0.63 & 0.16 & 3.86 & 0.35 & 2.05 & 1.01 & 0.21 & 0.83 & 0.14 & 0.05 \\
\hline Nissan & 0.68 & 0.23 & 2.94 & 0.48 & 1.34 & 0.08 & 0.07 & 1.19 & 0.37 & $<0.01$ \\
\hline Suzuki & 0.58 & 0.23 & 2.53 & 0.41 & 1.16 & 0.49 & 0.01 & 0.67 & 0.85 & $<0.01$ \\
\hline Toyota & 0.63 & 0.22 & 2.82 & 0.37 & 1.53 & 0.02 & 0.03 & 1.47 & 0.30 & 0.12 \\
\hline Fiat & 0.33 & 0.28 & 1.15 & 0.37 & 0.21 & 0.27 & 0.07 & -0.13 & -0.02 & 0.90 \\
\hline BMW & 0.51 & 0.20 & 2.56 & 0.35 & 1.14 & 0.66 & 0.02 & 0.46 & 0.24 & 0.14 \\
\hline DaimlerChrysler & 0.77 & 0.18 & 4.27 & 0.66 & 1.27 & 0.04 & 0.19 & 1.04 & 0.41 & 0.02 \\
\hline Volkswagen & 0.52 & 0.16 & 3.29 & 0.42 & 1.02 & 0.46 & 0.18 & 0.38 & 0.16 & 0.27 \\
\hline Peugeot & 0.27 & 0.25 & 1.08 & 0.13 & 0.69 & 0.33 & 0.04 & 0.32 & 0.03 & 0.80 \\
\hline Renault & 0.31 & 0.21 & 1.46 & 0.11 & 1.06 & 1.97 & 0.10 & -1.01 & 0.05 & 0.73 \\
\hline Mean & 0.55 & 0.22 & 2.70 & 0.38 & 1.26 & 0.41 & 0.09 & 0.76 & 0.18 & 0.29 \\
\hline Median & 0.59 & 0.22 & 2.69 & 0.39 & 1.15 & 0.23 & 0.08 & 0.75 & 0.15 & 0.14 \\
\hline
\end{tabular}




\section{Table 2: Sample Selection Statistics and Composition}

This table reports the effects of various sample selection criteria (Panel A) and industry and country composition of the final sample size (Panel B). A minimum of 25 monthly stock returns on Datastream are required for calculating exposures from the regression model. Accounting data are required for calculating many of the model input parameters and unlevering exposure estimates from the regression model. An annual report available in English on the Global Reports database is required for obtaining information on foreign currency debt and the use if foreign exchange derivatives. International trade data are from United Nations Industrial Development Organization (UNIDO) Industrial Statistics Database and the Structural Statistics for Industry and Services (SSIS) database of the OECD and are required for calculating measures of import competition. Finally, we require data on foreign sales and assets for both the sample firm and at least on foreign competitor in the same industry to calculate model exposure values. Panel B reports the ISIC industry names for the final sample.

Panel A. Sample Selection

\begin{tabular}{lc} 
Selection Criterion & Sample Size \\
\hline Manufacturing firms with stock returns on Datastream \& accounting data & 7,650 \\
Firms with annual report in English on Global Reports database & 2,668 \\
Firms with international trade data (available for 16 countries) & 2,149 \\
Firms (and competitors) with reported foreign sales and assets & 1,150 \\
\hline
\end{tabular}

Panel B. Industry and Country Composition

\begin{tabular}{|c|c|c|c|c|c|}
\hline Industry & Obs. & \% Sample & Country & Obs. & $\%$ Sample \\
\hline Aircraft & 21 & $1.8 \%$ & Australia & 18 & $1.6 \%$ \\
\hline Apparel & 13 & $1.1 \%$ & Austria* & 3 & $0.3 \%$ \\
\hline Automobiles & 65 & $5.7 \%$ & Canada & 74 & $6.4 \%$ \\
\hline Beer \& Liquor & 13 & $1.1 \%$ & Denmark & 2 & $0.2 \%$ \\
\hline Books & 14 & $1.2 \%$ & France* & 4 & $0.3 \%$ \\
\hline Business Services & 33 & $2.9 \%$ & Germany* & 28 & $2.4 \%$ \\
\hline Business Supplies & 31 & $2.7 \%$ & Indonesia & 2 & $0.2 \%$ \\
\hline Candy \& Soda & 13 & $1.1 \%$ & Ireland* & 1 & $0.1 \%$ \\
\hline Chemicals & 75 & $6.5 \%$ & Japan & 136 & $11.8 \%$ \\
\hline Computers & 49 & $4.3 \%$ & Mexico & 3 & $0.3 \%$ \\
\hline Construction Material & 58 & $5.0 \%$ & Netherlands* & 8 & $0.7 \%$ \\
\hline Consumer Goods & 50 & $4.3 \%$ & Norway & 1 & $0.1 \%$ \\
\hline Drugs & 101 & $8.8 \%$ & Singapore & 43 & $3.7 \%$ \\
\hline Electrical Equipment & 32 & $2.8 \%$ & Switzerland & 4 & $0.3 \%$ \\
\hline Electronic Equipment & 149 & $13.0 \%$ & United Kingdom & 152 & $13.2 \%$ \\
\hline Food Products & 32 & $2.8 \%$ & United States & 671 & $58.3 \%$ \\
\hline Lab Equipment & 56 & $4.9 \%$ & Memo: & & \\
\hline Machinery & 107 & $9.3 \%$ & EMU countries & 44 & $3.7 \%$ \\
\hline Medical Equipment & 62 & $5.4 \%$ & & & \\
\hline Oil & 19 & $1.7 \%$ & & & \\
\hline Other & 36 & $3.1 \%$ & & & \\
\hline Recreation & 19 & $1.7 \%$ & & & \\
\hline Retail & 11 & $1.0 \%$ & & & \\
\hline Rubber & 20 & $1.7 \%$ & & & \\
\hline Shipping Containers & 10 & $0.9 \%$ & & & \\
\hline Steel & 48 & $4.2 \%$ & & & \\
\hline Textiles & 13 & $1.1 \%$ & & & \\
\hline
\end{tabular}




\section{Table 3: Selected Descriptive Statistics for Sample}

The table reports descriptive sample statistics for selected variables. The mean, standard deviation and various percentiles of the variable distribution are reported. Foreign exchange rate exposures obtained from estimating equation (12) are labeled as regression exposure and are estimated using up to 60 (but not less than 25) months of local currency excess stock returns, excess local stock market index returns, and changes in trade-weighted exchange rate indices from 1998 to 2002. Regression exposure estimates are unlevered using total debt plus preferred stock. Foreign sales and foreign assets are as reported by Thomson Analytics. Foreign currency debt and FX derivatives dummy variables are obtained from searches of annual reports in 2000 or 2001 . Estimates are based on 1,150 firms. All variables are defined in Table A1 in the appendix.

\begin{tabular}{lrrrrrrr} 
& & & \multicolumn{5}{c}{ Percentiles } \\
\cline { 6 - 8 } & Mean & StdDev & 5 th & 25 th & Median & 75th & 95 th \\
\hline Regression Exposure & 0.160 & 1.972 & -3.435 & -0.701 & 0.280 & 1.260 & 3.139 \\
$\begin{array}{l}\text { Regression Exposure } \\
\text { (unlevered) }\end{array}$ & 0.090 & 1.621 & -2.965 & -0.466 & 0.174 & 0.837 & 2.487 \\
Foreign Sales & $34.6 \%$ & $27.3 \%$ & $0.0 \%$ & $11.6 \%$ & $31.9 \%$ & $53.5 \%$ & $85.9 \%$ \\
Foreign Assets & $19.2 \%$ & $21.7 \%$ & $0.0 \%$ & $2.3 \%$ & $12.3 \%$ & $27.8 \%$ & $67.0 \%$ \\
Foreign Currency Debt Dummy & 0.871 & & & & & & \\
FX Derivatives Dummy & 0.658 & & & & & & \\
Import Penetration & $24.1 \%$ & $17.3 \%$ & $3.4 \%$ & $11.8 \%$ & $21.1 \%$ & $32.8 \%$ & $59.1 \%$ \\
\hline
\end{tabular}


Table 4: Definitions of Parameters of the Global Competition Model

This table summarizes the variables, variable description and empirical counterpart for the global competition model. All empirical variables are defined in Table A1 in the appendix.

Variable Variable Description (where domestic/foreign are relative to each company's country of incorporation)

\begin{tabular}{|c|c|c|}
\hline$\phi$ & $\begin{array}{l}\text { Foreign sales as a percent of total } \\
\text { sales (FS) }\end{array}$ & Foreign sales as a percent of total sales $(F S)$ \\
\hline$(1-\phi)$ & $\begin{array}{l}\text { Domestic sales as a percent of total } \\
\text { sales }\end{array}$ & $\begin{array}{l}1 \text { - percentage of foreign sales as a percent of } \\
\text { total sales }(F S)\end{array}$ \\
\hline \multicolumn{3}{|c|}{$\begin{array}{l}\text { Exporting Firm } \\
\text { (domestic = country of exporter, foreign= country of import-competing firms) }\end{array}$} \\
\hline$\gamma_{f 1}$ & $\begin{array}{l}\text { Firm's fraction of marginal costs in } \\
\text { foreign currency (due to foreign } \\
\text { currency inputs or foreign } \\
\text { production) }\end{array}$ & Percentage of foreign assets of firm \\
\hline$\gamma_{f 2}$ & $\begin{array}{l}\text { Import competing firms' fraction of } \\
\text { marginal costs in the foreign } \\
\text { market/currency(s) (i.e., their } \\
\text { domestic market), also foreign } \\
\text { currency costs of other exporting } \\
\text { firms }\end{array}$ & $\begin{array}{l}\text { Weighted average of the percentage of domestic } \\
\text { assets of foreign firms and percentage of foreign } \\
\text { assets of other domestic firms, } \\
\text { i.e., weighted average of } \gamma_{d 2} \text { for foreign firms, } \\
\text { and } \gamma_{f 1} \text { for domestic firms in the same industry } \\
\text { (exporting also into the foreign market) }\end{array}$ \\
\hline$\lambda_{f}$ & $\begin{array}{l}\text { Market share of firm in foreign } \\
\text { markets }\end{array}$ & $\begin{array}{l}\text { Rest-of-world GDP-weighted average of import } \\
\text { penetration ratio }\end{array}$ \\
\hline
\end{tabular}

Import-Competing Firm

(domestic $=$ country of import-competitor, foreign=country of exporting firms)

\begin{tabular}{lll}
\hline & $\begin{array}{l}\text { Exporters' fraction of marginal } \\
\text { costs in the domestic } \\
\text { market/currency (i.e., their foreign } \\
\text { market), also domestic currency } \\
\gamma_{d 1}\end{array}$ & $\begin{array}{l}\text { Weighted average of the percentage of foreign } \\
\text { assets of foreign firms and percentage of } \\
\text { domestic assets of other domestic firms, } \\
\text { costs of other domestic, import- } \\
\text { competing firms }\end{array}$ \\
$\begin{array}{l}\text { Firm's fraction of marginal costs in } \\
\text { and } \gamma_{d 2} \text { for domestic firms in the same industry } \\
\text { (exporting also into the foreign market) } \\
\left(=1-\gamma_{f 1}\right)\end{array}$ & $\begin{array}{l}\text { Percentage of domestic assets of firm } \\
\text { the domestic currency }\end{array}$ \\
$\lambda_{d}$ & $\begin{array}{l}\text { Market share of import competing } \\
\text { firm in domestic market }\end{array}$ & 1 - domestic market import penetration ratio \\
\hline
\end{tabular}

Degree of product substitutability in $\rho_{f}, \rho_{d} \quad$ the foreign $(f)$ and domestic $(d)$ markets
Specified exogenously. In our empirical tests, we set $\rho_{f}=\rho_{d}=0.7$. However, we also frequently report results $\rho_{f}=\rho_{d}=0.5$ and $\rho_{f}=\rho_{d}$ $=0.9$. 


\section{Table 5: Summary Statistics of Parameters of the Global Competition Model}

This table reports summary statistics of model parameters for the global competition model. The table reports the mean, standard deviation, minimum, maximum and various percentiles of each variable distribution. Parameters are defined in Table 4. Estimates are based on 1,150 firms. Model exposure is calculated using equation (6) in the main text. Model pass-through is calculated using equation (10) in the main text. Both model exposure and passthrough are tabled for three different levels of product substitutability $\left(\rho_{f}=\rho_{d}=0.5,0.7,0.9\right)$.

Percentiles

\begin{tabular}{|c|c|c|c|c|c|c|c|c|c|}
\hline \multirow[b]{2}{*}{ Parameter } & \multirow[b]{2}{*}{ Mean } & \multirow[b]{2}{*}{ StdDev } & \multirow[b]{2}{*}{ Min } & \multicolumn{5}{|c|}{ Percentiles } & \multirow[b]{2}{*}{ Max } \\
\hline & & & & $5^{\text {th }}$ & $25^{\text {th }}$ & Median & $75^{\text {th }}$ & $95^{\text {th }}$ & \\
\hline \multicolumn{10}{|c|}{ Production Costs } \\
\hline$\gamma_{f 1}$ & 0.191 & 0.217 & 0.000 & 0.000 & 0.022 & 0.122 & 0.277 & 0.670 & 0.944 \\
\hline$\gamma_{d 1}$ & 0.631 & 0.170 & 0.000 & 0.286 & 0.548 & 0.675 & 0.741 & 0.846 & 0.945 \\
\hline$\gamma_{f 2}$ & 0.662 & 0.135 & 0.122 & 0.432 & 0.573 & 0.672 & 0.751 & 0.876 & 1.000 \\
\hline$\gamma_{d 2}$ & 0.809 & 0.217 & 0.056 & 0.330 & 0.723 & 0.878 & 0.978 & 1.000 & 1.000 \\
\hline \multicolumn{10}{|c|}{ Relative Costs } \\
\hline$\mu_{f}$ & 0.470 & 0.225 & -0.514 & 0.028 & 0.359 & 0.507 & 0.632 & 0.772 & 1.000 \\
\hline$\mu_{d}$ & 0.177 & 0.204 & -0.766 & -0.141 & 0.064 & 0.179 & 0.303 & 0.489 & 1.000 \\
\hline
\end{tabular}

Import Competition

$\begin{array}{llllllllll}\lambda_{f} & 0.294 & 0.126 & 0.009 & 0.085 & 0.230 & 0.287 & 0.369 & 0.537 & 0.754 \\ \lambda_{d} & 0.759 & 0.173 & 0.000 & 0.409 & 0.672 & 0.789 & 0.881 & 0.966 & 0.998\end{array}$

Model Exposure

$\rho_{f}=\rho_{d}=0.5$

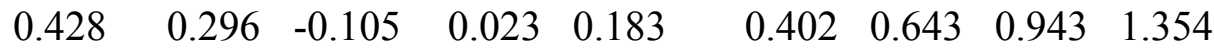

$\rho_{f}=\rho_{d}=0.7$

0.477

$\begin{array}{llll}0.316 & -0.169 & 0.036 & 0.222\end{array}$

$\begin{array}{llll}0.451 & 0.705 & 1.035 & 1.577\end{array}$

$\rho_{f}=\rho_{d}=0.9$

0.549

$\begin{array}{llll}0.355 & -0.247 & 0.052 & 0.269\end{array}$

$\begin{array}{llll}0.524 & 0.779 & 1.171 & 1.943\end{array}$

Model Pass-through

$\rho_{f}=\rho_{d}=0.5$

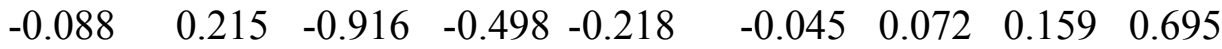

$\rho_{f}=\rho_{d}=0.7$

$\begin{array}{lllllllll}-0.061 & 0.218 & -0.883 & -0.470 & -0.195 & -0.028 & 0.096 & 0.203 & 0.695\end{array}$

$\rho_{f}=\rho_{d}=0.9$

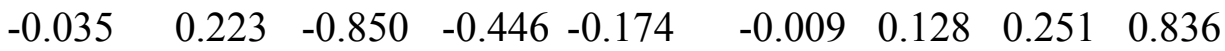




\section{Table 6: Firm and Industry Characteristics}

This table shows summary statistics for model exposures and firm characteristics for the global competition model with $\rho_{f}=\rho_{d}=0.7$. Panel A reports the mean, median and standard deviation of different variables for firms in the upper and lower tricile of model exposure (high and low, respectively). The breakpoint for high model exposure is 0.571 and the breakpoint for low model exposure is 0.293 . The last column presents $p$-values of Wilcoxon rank sum tests for differences between high and low exposure firms. Model exposure values are obtained from the global competition model. Regression exposures are obtained from empirical estimates of equity price exposure to changes in exchange rates from equation (12) using monthly data from 1998 to 2002. Panel B tables mean model and regression exposures for firms based on their use of FX derivatives and foreign currency (FC) debt. Estimates are based on 1,150 firms. Asterisks denote exposure values significantly different from zero at the $5 \%$ confidence level. All variables are defined in Table A1 in the Appendix.

\section{Panel A: By Model Exposure Tricile}

\begin{tabular}{|c|c|c|c|c|c|c|c|}
\hline \multirow[b]{2}{*}{ Variable } & \multicolumn{3}{|c|}{ High Model Exposure } & \multicolumn{3}{|c|}{ Low Model Exposure } & \multirow{2}{*}{$\begin{array}{r}\text { Wilcoxon } \\
p \text {-value }\end{array}$} \\
\hline & Mean & Median & StdDev & Mean & Median & StdDev & \\
\hline Model Exposure & 0.844 & 0.802 & 0.185 & 0.137 & 0.136 & 0.089 & \\
\hline Regression Exposure & 0.138 & 0.305 & 1.973 & 0.072 & 0.248 & 2.188 & 0.487 \\
\hline $\begin{array}{l}\text { Regression Exposure } \\
\text { (Unlevered) }\end{array}$ & 0.111 & 0.181 & 1.584 & -0.041 & 0.125 & 1.903 & 0.354 \\
\hline Foreign Currency Debt & 0.979 & 1.000 & 0.143 & 0.673 & 1.000 & 0.470 & $<0.001$ \\
\hline FX Derivatives & 0.789 & 1.000 & 0.409 & 0.421 & 0.000 & 0.494 & $<0.001$ \\
\hline Import Penetration & 0.301 & 0.255 & 0.195 & 0.177 & 0.146 & 0.120 & $<0.001$ \\
\hline $\begin{array}{l}\text { Foreign Import } \\
\text { Penetration }\end{array}$ & 0.284 & 0.277 & 0.126 & 0.281 & 0.267 & 0.122 & 0.491 \\
\hline Industry Herfindahl & 0.154 & 0.103 & 0.153 & 0.134 & 0.101 & 0.110 & 0.103 \\
\hline $\begin{array}{l}\text { Country-Industry } \\
\text { Herfindahl }\end{array}$ & 0.510 & 0.453 & 0.339 & 0.333 & 0.284 & 0.255 & $<0.001$ \\
\hline
\end{tabular}

Panel B: By Use of Foreign Currency Debt and FX Derivatives (means)

\begin{tabular}{lcccc} 
Variable & $\begin{array}{c}\text { Neither FX } \\
\text { Derivatives nor } \\
\text { FC Debt }\end{array}$ & $\begin{array}{c}\text { FX Derivatives } \\
\text { Only }\end{array}$ & FC Debt Only & $\begin{array}{c}\text { Both FX } \\
\text { Derivatives and } \\
\text { FC Debt }\end{array}$ \\
\hline $\begin{array}{l}\text { Model Exposure } \\
\begin{array}{l}\text { Regression Exposure } \\
\text { (Unlevered) }\end{array}\end{array}$ & 0.060 & 0.103 & $0.378^{* *}$ & $0.543^{* *}$ \\
\hline Number of Firms & -0.208 & 0.077 & 0.210 & 0.184 \\
\hline
\end{tabular}




\section{Table 7: Hedging Effects of Derivatives and Foreign Debt}

This table reports results of regressions of foreign currency debt and FX derivatives use on the difference between regression exposure and model exposure (equations 13a-13c). Model exposures are obtained from the global competition model in equation (6). Regression exposures are obtained from empirical estimates of equity price exposure to changes in exchange rates from equation (12) using monthly data from 1998 to 2002. The dependent variable is the difference between estimated (unlevered) regression exposure obtained from equation (12) and model exposure. Results are presented separately for different degrees of product substitutability $\left(\rho_{f}=\rho_{d}=0.5,0.7,0.9\right)$. For each regressor, the table shows the estimated coefficient and corresponding $p$-value. The models are estimated with data from 1,150 firms. All variables are defined in Table A1 in the appendix. Panel A reports results using dummy variables for FC debt and FX derivatives. Panel B reports results for dummy variables for i) only FC debt use, ii) only FX derivative use, and iii) use of both FC debt and FX derivatives.

Panel A: Model Specification Test

\begin{tabular}{|c|c|c|c|c|c|c|}
\hline \multirow[b]{2}{*}{$\rho_{f}=\rho_{d}$} & \multicolumn{2}{|c|}{ Intercept } & \multicolumn{2}{|c|}{ FC Debt } & \multicolumn{2}{|c|}{ FX Derivatives } \\
\hline & Coef. & $p$-value & Coef & $p$-value & Coef. & $p$-value \\
\hline 0.5 & -0.25 & $<0.001$ & & & & \\
\hline 0.7 & -0.30 & $<0.001$ & & & & \\
\hline 0.9 & -0.37 & $<0.001$ & & & & \\
\hline 0.5 & -0.07 & 0.495 & -0.21 & 0.059 & & \\
\hline 0.7 & -0.10 & 0.320 & -0.23 & 0.040 & & \\
\hline 0.9 & -0.15 & 0.161 & -0.26 & 0.020 & & \\
\hline 0.5 & -0.14 & 0.030 & & & -0.17 & 0.025 \\
\hline 0.7 & -0.18 & 0.005 & & & -0.19 & 0.017 \\
\hline 0.9 & -0.24 & $<0.001$ & & & -0.21 & 0.009 \\
\hline 0.5 & -0.05 & 0.604 & -0.12 & 0.310 & -0.14 & 0.114 \\
\hline 0.7 & -0.08 & 0.411 & -0.14 & 0.259 & -0.14 & 0.097 \\
\hline 0.9 & -0.13 & 0.225 & -0.16 & 0.185 & -0.16 & 0.073 \\
\hline
\end{tabular}

Panel B: Results for Alternative Hedging Strategies

\begin{tabular}{|c|c|c|c|c|c|c|c|c|}
\hline \multirow[b]{2}{*}{$\rho_{f}=\rho_{d}$} & \multicolumn{2}{|c|}{ Intercept } & \multicolumn{2}{|c|}{$\begin{array}{l}\text { Dummy for } \\
\text { FC Debt Only }\end{array}$} & \multicolumn{2}{|c|}{$\begin{array}{c}\text { Dummy for } \\
\text { FX Derivatives Only }\end{array}$} & \multicolumn{2}{|c|}{$\begin{array}{l}\text { Dummy } \\
\text { for Both }\end{array}$} \\
\hline & Coef. & $p$-value & Coef. & $p$-value & Coef. & $p$-value & Coef. & $p$-value \\
\hline 0.5 & -0.04 & 0.698 & -0.14 & 0.294 & -0.23 & 0.470 & -0.27 & 0.023 \\
\hline 0.7 & -0.07 & 0.495 & -0.15 & 0.254 & -0.23 & 0.472 & -0.29 & 0.015 \\
\hline 0.9 & -0.12 & 0.287 & -0.18 & 0.193 & -0.23 & 0.475 & -0.33 & 0.007 \\
\hline
\end{tabular}




\section{Table 8: Exposure Attribution Analysis}

This table calculates global competition model exposures using equation (6) to demonstrate the relative importance of different channels for exchange rate risk reduction. The first row considers an atomistic firm $\left(\lambda_{f}=\lambda_{d}=0\right.$ and therefore limited ability to pass-through exchange rate changes) with no operational hedging ( $\gamma_{f 1}$ $\left.=0, \gamma_{d 2}=1\right)$ and no financial hedging. The next row considers a firm with average market share in both the domestic and foreign markets $\left(\lambda_{f}=0.294, \lambda_{d}=0.759\right)$ but still no operational or financial hedging. The third row considers a firm with average market share in both the domestic and foreign markets $\left(\lambda_{f}=0.294, \lambda_{d}=0.759\right)$, the average level of foreign assets $\left(\gamma_{f 1}=0.192, \gamma_{d 2}=0.808\right)$, but no financial hedging. The fourth row considers a firm with average market share in both the domestic and foreign markets $\left(\lambda_{f}=0.294, \lambda_{d}=0.759\right)$, the average level of foreign assets $\left(\gamma_{f 1}=0.192, \gamma_{d 2}=0.808\right)$, and a reduction in the hedge ratio consistent with the coefficient estimates for users of FC debt and FX derivatives presented in Panel B of Table 7 as measures of financial hedging. Results are presented separately for different degrees of product substitutability $(\rho)$. For comparison, median unlevered regression exposure is presented in the last row and is obtained from empirical estimates of equity price exposure to changes in exchange rates from equation (12) using monthly data from 1998 to 2002.

\begin{tabular}{|c|c|c|c|c|c|c|}
\hline \multirow[b]{2}{*}{ Scenario } & \multicolumn{2}{|c|}{$\rho_{f}=\rho_{d}=0.5$} & \multicolumn{2}{|c|}{$\rho_{f}=\rho_{d}=0.7$} & \multicolumn{2}{|c|}{$\rho_{f}=\rho_{d}=0.9$} \\
\hline & $\begin{array}{l}\text { Model } \\
\text { Exposure } \\
\text { Estimate } \\
\end{array}$ & $\begin{array}{c}\text { Marginal } \\
\text { Change } \\
(\% \text { of Base }) \\
\end{array}$ & $\begin{array}{l}\text { Model } \\
\text { Exposure } \\
\text { Estimate } \\
\end{array}$ & $\begin{array}{l}\text { Marginal } \\
\text { Change } \\
(\% \text { of Base }) \\
\end{array}$ & $\begin{array}{l}\text { Model } \\
\text { Exposure } \\
\text { Estimate } \\
\end{array}$ & $\begin{array}{l}\text { Marginal } \\
\text { Change } \\
(\% \text { of Base }) \\
\end{array}$ \\
\hline $\begin{array}{l}\text { Low Pass-through }\left(\lambda_{f}=\lambda_{d}=0\right) \text {, } \\
\text { No Operational Hedging }\left(\gamma_{f 1}=0, \gamma_{d 2}=1\right) \text {, } \\
\text { No Financial Hedging }\end{array}$ & 0.581 & & 0.675 & & 0.769 & \\
\hline $\begin{array}{l}\text { Pass-through }\left(\lambda_{f}=0.294, \lambda_{d}=0.759\right) \text {, } \\
\text { No Operational Hedging }\left(\gamma_{f 1}=0, \gamma_{d 2}=1\right) \text {, } \\
\text { No Financial Hedging }\end{array}$ & 0.487 & $-16.2 \%$ & 0.572 & $-15.3 \%$ & 0.695 & $-9.6 \%$ \\
\hline $\begin{array}{l}\text { Pass-through }\left(\lambda_{f}=0.294, \lambda_{d}=0.759\right) \text {, } \\
\text { Operational Hedging }\left(\gamma_{f 1}=0.192, \gamma_{d 2}=0.808\right) \text {, } \\
\text { No Financial Risk Management }\end{array}$ & 0.436 & $-8.7 \%$ & 0.491 & $-12.0 \%$ & 0.571 & $-16.1 \%$ \\
\hline $\begin{array}{l}\text { Pass-through }\left(\lambda_{f}=0.294, \lambda_{d}=0.759\right) \text {, } \\
\text { Operational Hedging }\left(\gamma_{f 1}=0.192, \gamma_{d 2}=0.808\right) \text {, } \\
\text { Financial Hedging }\end{array}$ & 0.166 & $-46.5 \%$ & 0.201 & $-42.9 \%$ & 0.241 & $-42.9 \%$ \\
\hline Total Reduction in Exposure & & $-71.4 \%$ & & $-70.2 \%$ & & $-68.6 \%$ \\
\hline Regression Exposure (Median Unlevered) & 0.174 & & 0.174 & & 0.174 & \\
\hline
\end{tabular}




\section{Table 9: Analysis of Additional Firm-Specific Variables}

The table reports the results of regressions of financial risk management dummy variables and additional firm characteristics on the differences (or absolute differences) between unlevered regression exposures and model exposures. The first column repeats the values provided in Panel B of Table 7 as a benchmark. For each regressor, the table shows the estimated coefficient (coef.) and corresponding $p$-value ( $p$-val.). Country and industry dummy variables are included in specifications 3 and 4 . Results are from OLS regressions or, as indicated, weighted least squares regressions with the inverse of the standard error of regression exposure estimates from equation (12) as the weights. The table also shows the number of observations used in the regression and the adjusted $\mathrm{R}^{2}$. Regression exposures are obtained from empirical estimates of equity price exposure to changes in exchange rates from equation (12) using monthly data from 1998 to 2002. All variables are defined in Table A1 in the appendix.

(1)

\begin{tabular}{|c|c|c|c|c|c|c|c|c|}
\hline & Coef. & $p$-val. & Coef. & $p$-val. & Coef. & $p$-val. & Coef. & $p$-val. \\
\hline Intercept & -0.07 & 0.50 & -0.05 & 0.64 & 0.13 & 0.36 & -0.02 & 0.85 \\
\hline FC Debt Only Dummy & -0.15 & 0.25 & -0.15 & 0.23 & -0.37 & 0.02 & -0.19 & 0.19 \\
\hline FX Derivatives Only Dummy & -0.23 & 0.46 & -0.17 & 0.59 & -0.49 & 0.15 & -0.19 & 0.55 \\
\hline $\begin{array}{l}\text { Both FC Debt and FX } \\
\text { Derivatives Dummy }\end{array}$ & -0.29 & 0.01 & -0.22 & 0.05 & -0.53 & $<0.01$ & -0.32 & 0.02 \\
\hline Size (log) & & & & & 0.00 & 0.96 & -0.03 & 0.44 \\
\hline Gross Profit Margin & & & & & 0.06 & 0.19 & 0.03 & 0.55 \\
\hline Tangible Assets & & & & & -0.08 & 0.07 & -0.07 & 0.07 \\
\hline Number of Industry Segments & & & & & 0.01 & 0.80 & 0.05 & 0.18 \\
\hline Debt Maturity & & & & & 0.04 & 0.31 & 0.02 & 0.51 \\
\hline Dividend Dummy & & & & & 0.13 & $<0.01$ & 0.11 & $<0.01$ \\
\hline Current Ratio & & & & & -0.06 & 0.32 & -0.02 & 0.68 \\
\hline $\begin{array}{l}\text { Country \& Industry } \\
\text { Dummy Variables }\end{array}$ & No & & No & & Yes & & Yes & \\
\hline Weighting & & & $1 / \mathrm{SE}$ & & & & $1 / \mathrm{SE}$ & \\
\hline Observations & 1150 & & 1150 & & 969 & & 969 & \\
\hline Adjusted $\mathrm{R}^{2}$ & 0.05 & & 0.06 & & 0.08 & & 0.11 & \\
\hline
\end{tabular}




\section{Table 10: Feasibility of Financial Hedging Estimates}

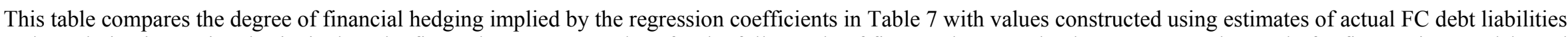

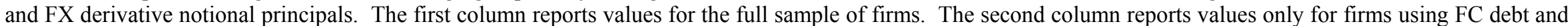

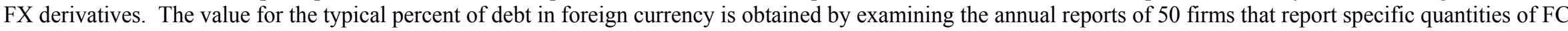

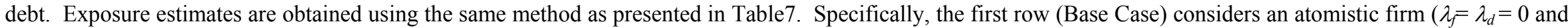

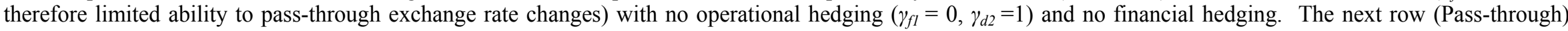

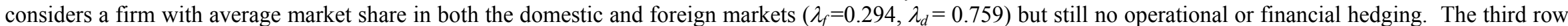

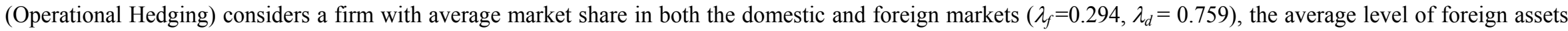

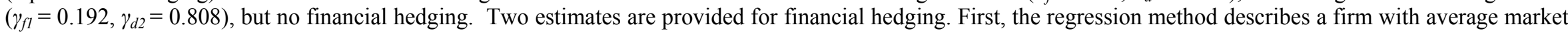

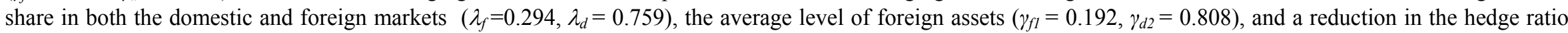

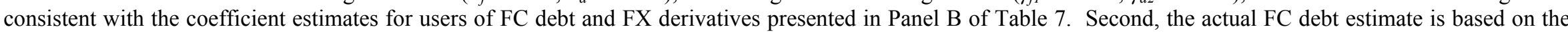

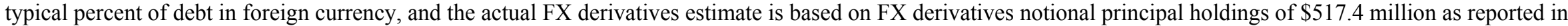

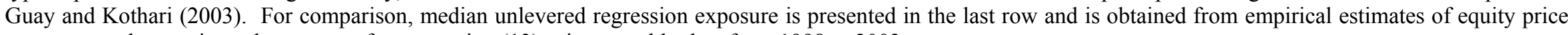
exposure to changes in exchange rates from equation (12) using monthly data from 1998 to 2002.

All Sample Firms User Subsample

Market Capitalization (USD millions)
Leverage
Total Debt (USD millions)
Typical Percent of Debt in Foreign Currenc

$4,770.3$

$6,205.0$

Typical Percent of Debt in Foreign Currency

Model

Exposure

\section{Base Case}

Estimate

Pass-through

0.675

Operational Hedging

0.572

0.491

$-42.9 \%$

$-42.7 \%$

i. Regression Method

ates

0.350

$-25.4 \%$

ii. Actual FC Debt Estimates

0.451

$-11.5 \%$

Actual FX Derivatives Estimates

0.266

Regression Exposure (Median Unlevered)

0.174

0.192 


\section{Table A1: Variable Definitions}

The table reports the variables of the study and their definition. Panel A refers to firm characteristics and Panel B to industryspecific and country-specific variables.

\begin{tabular}{|c|c|}
\hline Variable & Definition \\
\hline \multicolumn{2}{|l|}{ Panel A: Firm Characteristics } \\
\hline Foreign Sales & International Sales / Net Sales or Revenues \\
\hline Foreign Assets & International Assets / Total Assets \\
\hline Foreign Production & International Production / Total Production (from WARDS) for automakers \\
\hline Regression Exposure & $\begin{array}{l}\text { Foreign exchange rate exposure from a regression of changes in the local } \\
\text { stock market index in excess of the risk-free rate and changes in a trade- } \\
\text { weighted foreign exchange rate index (in local currency relative to foreign } \\
\text { currency) on stock returns in excess of the risk-free rate }\end{array}$ \\
\hline $\begin{array}{l}\text { Regression Exposure } \\
\text { (Unlevered) }\end{array}$ & Leverage-adjusted value of Regression Exposure \\
\hline FX Derivatives & Dummy variable with value 1 if firm uses FX derivatives; 0 otherwise \\
\hline Foreign Currency (FC) Debt & $\begin{array}{l}\text { Dummy variable with value } 1 \text { if any foreign currency debt is reported; } 0 \\
\text { otherwise }\end{array}$ \\
\hline Size $(\log )$ & $\begin{array}{l}\text { Natural logarithm of the sum of market capitalization, total debt and preferred } \\
\text { stock }\end{array}$ \\
\hline Gross Profit Margin & Gross Income / Net Sales or Revenues (3 year average) \\
\hline Tangible Assets & $\begin{array}{l}\text { (Total Assets - Intangibles) / Total Assets. Intangibles assets include items } \\
\text { such as goodwill cost in excess of net assets purchased, patents, copyrights, } \\
\text { trademarks, etc. }\end{array}$ \\
\hline Number of Industry Segments & $\begin{array}{l}\text { Number of business segments (4-digit SIC codes) that make up the company's } \\
\text { revenue (between } 1 \text { and } 8 \text { ) }\end{array}$ \\
\hline Leverage & Total Debt / sum of market capitalization, total debt and preferred stock \\
\hline Debt Maturity & $\begin{array}{l}\text { Total Long-Term Debt / Total Debt. Long-term debt represents debt } \\
\text { obligations due more than one year from the company's balance sheet date or } \\
\text { due after the current operating cycle }\end{array}$ \\
\hline Dividend Dummy & $\begin{array}{l}\text { Dummy variable with value } 1 \text { if dividend yield, dividend payout or dividend } \\
\text { per share is positive; } 0 \text { otherwise }\end{array}$ \\
\hline Quick Ratio & Sum of cash and short term investments / Total Assets \\
\hline \multicolumn{2}{|c|}{ Panel B: Industry and Country Characteristics } \\
\hline Average Margin & Average of Gross Profit Margin for firms in the same industry \\
\hline Import Penetration & Industry Imports / (Industry Production + Industry Imports) \\
\hline Foreign Import Penetration & $\begin{array}{l}\text { GDP-weighted average of Import Penetration for the same industry in all } \\
\text { foreign countries }\end{array}$ \\
\hline Country-Industry Herfindahl & Herfindahl index based on sales by country and industry \\
\hline Industry Herfindahl & Herfindahl index based on sales by industry \\
\hline
\end{tabular}

